\title{
Hedonic and Environmental Quality: a hybrid model of product differentiation*
}

\author{
Andrea Mantovani†, Ornella Tarola ${ }^{\ddagger}$ and Cecilia Vergari ${ }^{\S}$
}

May 26, 2016

\begin{abstract}
In this paper, we analyze how strategic competition between a green firm and a brown competitor develops when their products are differentiated along two dimensions: hedonic quality and environmental quality. The former dimension refers to the pure (intrinsic) performance of the good, whereas the latter dimension has a positional content: buying green goods satisfies the consumer's desire to be portrayed as a socially worthy citizen. We consider the case in which these quality dimensions are in conflict with each other so that the higher the hedonic quality of a good, the lower the corresponding environmental quality. We characterize the equilibrium configurations and discuss the policy implications deriving from our analysis.
\end{abstract}

Keywords: Hedonic quality, environmental quality, relative preferences.

JEL Classification: D62; L13; H13.

\footnotetext{
${ }^{*}$ We are very grateful to the Associate Editor Sangeeta Bansal and to two anonymous referees for very detailed comments that have led to substantial improvements of the paper. We are also thankful to Paul Belleflamme, Joan Calzada, Miguel Carriquiry, Jean J. Gabszewicz, Luca Lambertini, Ester Manna, Anna Montini, Arsen Palestini, Francisco Ruiz-Aliseda, Francesca Sanna-Randaccio, Roberta Sestini, Alessandro Tampieri, Edilio Valentini, Skerdilajda Zanaj and the audience at ERMES (Université Pantheon Assas, Paris II), Pontificia Universidad de Chile, Universidad de Barcelona, UECE Lisbon Meetings in Game Theory and Applications 2015, Universidad de la República Uruguay, and University of Bologna, for precious comments and discussion. We thank Lucy Scioscia for editorial assistance. The usual disclaimer applies.

${ }^{\dagger}$ Department of Economics, University of Bologna, Strada Maggiore 45, 40125 Bologna, Italy, and Barcelona Institute of Economics (IEB), C/ J. M. Keynes 1-11, 08034 Barcelona, Spain; email: a.mantovani@unibo.it.

${ }^{\ddagger}$ Department of Economics and Social Sciences, University of Rome "La Sapienza"; email: ornella.tarola@uniroma1.it.

${ }^{\S}$ Department of Economics, University of Bologna, Strada Maggiore 45, 40125 Bologna, Italy, email: cecilia.vergari@unibo.it
} 


\section{Introduction}

In this paper, we analyze how strategic competition between a green firm and a brown competitor develops when their products are differentiated along two dimensions: hedonic quality and environmental quality. The former dimension refers to the pure (intrinsic) performance of the good, whereas the latter dimension has a positional content: buying "green" goods satisfies the consumer's desire to be portrayed as a socially worthy citizen. We consider the case in which these quality dimensions are in conflict with each other so that the higher the hedonic quality of a good, the lower the corresponding environmental quality. Finally, we evaluate the impact of a minimum quality standard, and compare our results with those deriving from a traditional model of vertical differentiation. ${ }^{1}$

Two main considerations inspire our analysis. First of all, people are increasingly concerned with environmental issues. This may be driven by personal interests, as caring about the environment also means caring about their own health and safety (Ostrom, 2000; Heffner et al., 2007; Carlsson et al., 2010, Deltas et al. 2013). Recent analysis also suggests that, when deciding about buying green goods, people are particularly sensitive to psychological and social concerns (Bateson et al. 2006). In 2007, the New York Times reported the top five reasons why Toyota Prius owners bought their hybrid cars. The main reason was that "it shows the world that its owner cares" ${ }^{2}$, while having "only a basic understanding of environmental issues or the ecological benefits of HEVs (hybrid electric vehicles)" as pointed out by Heffner et al. (2007, p. 409). An environmentally friendly product may contribute to satisfy the desire to stand out as socially worthy (Ostrom, 2000), thereby providing buyers with some social/psychological benefits beyond the material needs that products traditionally satisfy. ${ }^{3}$ On the contrary, when purchasing "brown" products, consumers may incur a social stigma as they fail to comply with a social/psychological norm of responsible citizens. ${ }^{4}$ Drawing on this behavioral frame, one can explain for example why people are more likely to offer money in a public goods game to protect the environment when the giving is done publicly and thus visible to others (Milinski et al., 2006). The same argument also explains why home owners tend to overinvest in solar panels and underinvest in other green home improvements, such as additional insulation and

\footnotetext{
${ }^{1}$ Interestingly, this issue has been recently addressed by the European Commission in the Energy Union Package, where for the first time, the EU stated that consumers can play a key role in fighting pollution.

${ }^{2}$ http://www.nytimes.com/2007/07/04/business/04hybrid.html?_r=0\#addendums

${ }^{3}$ Notice that this positional content has no direct relationship with the current regulation adopted in a specific country. Case in point, the automotive emissions standards set by the European Union. Two types of cars can meet the requirements, while having different emissions levels. From the EU viewpoint, both of them are sufficiently green and therefore do not incur any restriction to their circulation. However, from the consumers' viewpoint, the less pollutant the car, the more significant the contribution to the environment and therefore the better the social image they obtain.

${ }^{4}$ If consumers buy a product which lacks any environmental friendly characteristics, they might be burdened by a bad conscience since it is expected that people be environmentally aware. (Conrad, 2005).
} 
window caulking; while the former investment is conspicuous and therefore it provides some social benefits, the latter is not. ${ }^{5}$ Green consumption is a byword for good citizenship, likewise brown purchasing leads to a blameworthy social image. A consumption behavior contributes to define the social traits of an individual, thus its relative position among peers. Accordingly, the higher the relative environmental quality of a good, namely its ranking along the quality ladder, the higher its social value and the corresponding position it confers to the buyer along the social ladder. This represents the first ingredient of our analysis.

However, if this is the case, then why are brown goods still so popular? First of all, producing high quality goods does not necessarily imply a trade-off between the hedonic and the environmental dimensions. In some sectors, such as cosmetics, household and sometimes food, high hedonic quality standards can be obtained without sacrificing the environmental quality. Typical examples are given by non-animal tested cosmetics, ultra-concentrated detergents and dolphin-safe tuna. On the contrary, in other sectors, this trade-off is inevitable as certain brown goods meet consumers' requirements better than the green alternatives (Carrigan and Attalla, 2001; Gupta and Ogden 2009, Weatherell et al., 2003). For example, conventional internal combustion engine vehicles, although dominated by green alternatives in terms of polluting emissions, are still superior in most cases to electric or hybrid vehicles based on pure performance. Paper produced from trees instead of recycled paper is often preferred because it is softer to the touch. The reprocessing of recycled plastic can be more challenging compared with virgin plastic. New generation washing machines have energy saving cycles labeled "green" or "eco"; they are, however, more time consuming in comparison with ordinary cycles. As Conrad states: "Although nowadays ecologically relevant behavior is expected from a consumer, there are still consumers who buy canned beer or bottled juice under a no refund claim system instead of buying beverages under the deposit-refund system. [...] They buy cars with a big engine and a bad mileage per liter gasoline instead of a threeliter car. They prefer to use the airplane instead of the train although of a relatively short travel distance, they purchase conventional bulbs instead of electricity saving bulbs or they prefer energy-inefficient halogen light instead of neon tubes" (Conrad, 2005, p. 1). Whatever the intrinsic driver to brown consumption, "there is a trade-off between utility derived from preferred characteristics of a product and the moral behavior of buying "green", expected by part of the society.[...] Producers are aware of the conflict of consumers between preferred characteristics and their environmental incompatibility. They know that customers, getting their preferred characteristics from an environmental friendly product, welcome that coincidence but if environmental aspects are missing, they might anyhow buy the product" (Conrad, 2005, p. 2). An immediate by-product of this discussion is that, when the aforementioned

\footnotetext{
${ }^{5}$ Since Veblen (1899), this behavior has been well described by the theory of conspicuous consumption, in which the utility (or status) of a consumer depends, at least partially, on the comparison between her own consumption decision (and the quality of the product she buys) and that of others. Under conspicuous consumption, consumers are willing to pay a higher price for a functionally equivalent good in order to reveal their wealth, their social status or other specific characteristics. See Bagwell and Bernheim (1996) and Bowles and Park (2005) for recent contributions.
} 
trade-off is evident, the ranking of a good along the quality ladder mainly depends on the importance that people attach to its environmentally friendly nature as compared to other attributes. The existence of a conflict between the social component of consumption and the individual-rationality-based motive constitutes the second ingredient of our analysis.

\section{The modeling framework: a hybrid category of product differentiation}

In order to formalize the above ingredients, we define a market consisting of two firms providing differentiated goods to a population of consumers. The functionality of a product determines its hedonic quality so that goods can be ranked along a quality ladder based on their performance. The variant characterized by a better (resp. lower) performance is thus the high (resp. low) quality good in terms of hedonic quality. Nonetheless, the better is its performance, the more polluting is the good.

Moreover, we assume that the utility deriving from consuming a product also depends on the environmental quality gap between this variant and the other available in the market, thereby nesting the notion of relative preferences in the utility function. From a theoretical perspective, this modeling choice directly derives from the models of vertical product differentiation with $n$ firms, where $n \geq 2$. In this framework, apart from its own profits, only the payoffs of the adjacent rivals matter for the strategic behavior of a firm. Consistently with this, its profits are determined by the quality gap between the quality of its own variant and those of the adjacent ones. Our formulation preserves this property and it enables us to compare the predictions of our model with those coming from a traditional vertically differentiated market. ${ }^{6}$ A further justification for the adoption of relative preferences lies on the empirical ground. Recent initiatives launched by public authorities provide comparative information on the main characteristics of products. They aim at explaining the harmful effects of poor consumption habits on the environment. For example, in the automotive sector, an increasing number of informative campaigns have been promoted, such as the Italian guidelines on $\mathrm{CO}_{2}$ emission savings, ${ }^{7}$ the EPA Smart Way program in the US, ${ }^{8}$ and the Green Vehicle Guide promoted by the Australian government. ${ }^{9}$ A common trait among these campaigns is that they all compared the environmental performance of vehicles. Relative preferences make the choice between the two variants far from being evident, and add a further dimension of product heterogeneity with unexpected effects on the traditional mechanism of competition between firms in a vertically differentiated market.

\footnotetext{
${ }^{6}$ We refer the interested reader to Scarpa (1998) and Gabszewicz et al. (2016) for an in-depth analysis of this property.

${ }^{7}$ The Italian guidelines are a joint initiative promoted by the Ministry of Transportation, the Ministry of Economic Development and the Ministry of Environment. For further details, visit www.mit.gov.it/mit/site.php? $\mathrm{p}=\mathrm{cm} \& \mathrm{o}=\mathrm{vd} \& \mathrm{id}=2724$.

${ }^{8}$ Visit www.epa.gov/smartway/basic-info/index.htm for further details. The Environmental Protection Agency (EPA) is a U.S. federal government agency created for the purpose of protecting human health and the environment by enforcing regulations based on laws passed by Congress.

${ }^{9}$ Visit http://www.greenvehicleguide.gov.au/GVGPublicUI/home.aspx for further information.
} 
In case of vertical differentiation, by definition, when two variants are marketed at the same price, then all consumers prefer the high-quality variant as they all agree on the ranking of products on the quality ladder. In our setting, competition between firms is described by a model of vertical differentiation sensu stricto as long as all consumers agree that the hedonic quality of a product is more valuable than its green nature (or the reverse!). However, if a product is better than the alternative based on one characteristic but worse than it based on another one, then the defining property of vertical differentiation may cease to hold. This occurs whenever some consumers give more value to the hedonic dimension of a variant while others privilege its environmental quality. In this case, at the same price, some consumers buy a certain good, whereas others prefer the one produced by the rival. Although this feature evokes a model of horizontal differentiation, its traditional result that symmetric firms set an equal price at equilibrium can never be observed. The asymmetry between firms stemming from the two dimensions of product differentiation is such that, when the defining property of vertical differentiation stops holding, competition falls into a hybrid category where, at equal prices, both variants have a positive demand (horizontal differentiation) but at equilibrium their prices do not coincide (vertical differentiation). ${ }^{10}$

This hybrid category of product differentiation opens the door to several results which are not observed in a traditional vertically differentiated market. First, we observe that, when both firms are active at equilibrium, there exist circumstances in which the price of the green good (the low hedonic quality product) ceases to be lower than the price of the competing variant. We label this scenario duopoly with price switch. Second, we find that, whenever the intensity of relative preferences is sufficiently high, only the green firm can remain active, while the "dirty" competitor is pushed off the market. Thus, a green monopoly is observed. On the contrary, a brown monopoly occurs when the hedonic quality is by far more significant for consumers than the environmental friendly attribute. It is worth noting that a monopoly configuration can be observed in a vertically differentiated setting only under a restrictive assumption on consumer heterogeneity (natural monopoly). Third, at the green monopoly equilibrium configuration, for extremely high intensity of relative preferences, the green monopolist extends the market coverage farther than what is typically observed in a vertically differentiated setting, thereby determining a covered green monopoly.

In the second part of the paper, we develop some policy considerations and analyze the role of a minimum quality standard in the form of unit emission standards. ${ }^{11}$ These standards are widespread in the US. In 2015, President Obama, and EPA's Administrator Gina McCarthy, defined the final Clean Power Plan, by which achievable standards were agreed upon. The aim was a 32 percent

\footnotetext{
${ }^{10}$ There is a strand of literature considering different sources of product differentiation. For example, Gabszewicz and Thisse (1986), Neven and Thisse (1990), and Gabszewicz and Wauthy (2012) combine horizontal and vertical differentiation. Other contributions consider multiple vertical dimensions, such as Vandenbosch and Weinberg (1995) and Lauga and Ofek (2011).

${ }^{11}$ Mantovani and Vergari (2013) consider the role of environmental campaign vs. taxation under relative preferences.
} 
reduction in carbon emissions from 2005 levels to be reached by $2030 .{ }^{12}$ In Europe, several standards have been introduced to fight climate change. Case in point, EU legislation defines mandatory emission reduction targets for new vehicles. ${ }^{13}$ At world level, in occasion of the Paris Climate Change Conference held in November 2015, more than 190 countries declared their willingness to cut emissions. ${ }^{14}$ We consider whether a relevant effect on the environmental damage can be obtained when the environmental quality standard is between the green variant and the brown one. In this circumstance only the brown producer undertakes an abatement effort, the green rival being unaffected by the standard. Also, we assume that the abatement effort improves the environmental quality of the good at the expense of the corresponding hedonic quality (Boucekkine et al., 2011). Since complying with stricter environmental norms is costly, when a firm invests in cleaner technology, it may sacrifice its own economic productivity, at least in a short-run perspective. ${ }^{15}$ In the literature on vertical differentiation, typically the introduction of a minimum quality standard in a duopoly setting reduces product differentiation, thereby increasing price competition (Crampes and Hollander 1995, Ecchia and Lambertini 1997, Ronnen 1991). A by-product of this finding is that a priori a minimum quality standard raises the environmental damage (Moraga Gonzales and Padron-Fumero, 2002). In particular, this undesirable effect is observed when the total output sold at the market equilibrium increases, due to the price reduction. This also occurs when the polluting firm steals consumers from the green rival as a consequence of a milder product differentiation. A reduction of emissions coming from a lower market share of the green firm is countervailed by the increase of emissions deriving from a larger market share gained by the polluting rival. In our paper, the trade-off between the two vertical attributes, environmental quality and hedonic quality, are such that this effect is not always present. In particular, a reduction in damage may be observed under duopoly. This occurs when the market share stolen by the brown producer is not very significant, due to the high valuation of consumers for the hedonic attribute. Furthermore, under uncovered green monopoly, the investment of the brown producer unambiguously reduces the environmental damage.

The structure of the paper is as follows. In Section 2 we present the related literature. In Section 3 we set up the baseline model. In Section 4 we develop the equilibrium analysis. In Section 5 we present some environmental policy considerations. Section 6 provides a discussion of our main assumptions. Section 7 concludes.

\footnotetext{
${ }^{12}$ Visit https://www.whitehouse.gov/climate-change for more information.

${ }^{13}$ Visit http://ec.europa.eu/clima/policies/transport/vehicles/cars/index_en.htm.

${ }^{14} \mathrm{It}$ is worth noting that, instead of introducing mandatory emissions limits, the Paris agreement adopted a bottom-up approach, by which each country can determine its own actions in order to meet the standard. This strategy has been supported by many climate change experts, especially after the unsatisfying conference in Copenhagen in 2009, which was based on a top-down approach.

${ }^{15}$ Admittedly, some argue that there is no way to offset this trade-off regardless of the time horizon (Luken et al. 1996), while others suggest that in the long-run, attaining better technologies in all respects (both environmental and hedonic dimensions) is feasible (Boucekkine et al., 2011). This statement can be better viewed in a dynamic perspective where improving the environmental standards entails further cost-reducing or productivity-enhancing innovation (see for example the analysis by Porter and Linde, 1995).
} 


\section{Related Literature}

Throughout the course of the last decade, increasing attention has been devoted to the impact of environmental awareness on market equilibrium (Conrad, 2005; Eriksson, 2004; García-Gallego and Georgantzís, 2009; Lombardini-Riipinen 2005; Moraga-Gonzalez and Padron-Fumero, 2002; Nyborg et al., 2006; Rodriguez-Ibeas, 2007; Ben Elhadj and Tarola, 2015, inter alia).

However, to the best of our knowledge, we are the first to combine in a unified setting of vertical differentiation the notion of relative preferences and the possibility of a conflict between traditional hedonic qualities and newly established environmental qualities. To this aim, we borrow some ingredients from the paper by Conrad (2005) and nest them in a formal setting inspired by Ben Elhadj and Tarola (2015). The former work considers the possible conflict between the satisfaction derived from the preferred characteristics of a product and the moral behavior of buying "green" in a horizontal differentiation setting. The latter is based instead on a vertically differentiated setting where relative preferences are explicitly taken into account, as people seek a relative position among peers and buy products also for their social value. We share with Conrad (2005) the view that this conflict can modify traditional consumers' preferences and, accordingly, it must be incorporated directly into the utility function. ${ }^{16}$ Nevertheless, we depart from his model as our analysis is conceived in a setting where goods are defined on the basis of two vertical attributes. Furthermore, far from Conrad (2005), we assume that both the social benefit and the social stigma attached to buyers increase with the environmental quality gap between variants. Thus, we combine his view with the notion of relative preferences adopted by Ben Elhadj and Tarola (2015). This nesting enables us to extend their analysis. Indeed, they confine their work to the case in which a variant is simultaneously of higher hedonic quality and more environmentally friendly than the alternative. Accordingly, it never arises a conflict for the consumer between the pure performance of a product and the social image that can be associated to its consumption. As a matter of fact, often this conflict does not arise. For example, Ben Elhadj and Tarola (2015) argue that the social/psychological drivers work unevenly worldwide, since the sense of responsibility to protect the environment belongs to a set of values arising among wealthy people after their basic needs have been met. Moreover, as previously reported, there exist many examples of goods satisfying both high environmental standards without sacrificing their intrinsic quality. Still, their analysis misses to formalize the large amount of evidence testifying that consumers can face a conflict. As such, our paper can be intended as a natural complement of their work, leading to a new set of results and equilibrium configurations.

Our analysis is finally linked to a significant stream of the behavioral economics literature studying pro-environmental conduct (for a detailed review, see Turaga et al., 2010). This literature aims at explaining the discrepancy between the predictions of the economic models based on the homo economicus assumption and the empirical evidence on the voluntary contribution to public goods.

\footnotetext{
${ }^{16}$ In Section 2 we discuss at length how our utility function differs from that modeled by Conrad (2005).
} 
Drawing insights from social psychology, the idea is to extend the standard models incorporating the incentive coming from moral/social motivation. Besides the important works by Andreoni (1988, 1990), there are many recent theoretical as well as empirical contributions in the ecological economics literature (see among others, Brekke et al., 2003; Nyborg et al., 2006; Manner and Gowdy, 2010; Owen and Videral, 2006) analyzing the formation of pro-environmental behaviors. While we take inspiration from this literature, we depart from it as we do not endogenize the moral/social incentive to pro-environmental conduct. Rather, we study how it affects market competition (and in turn the environmental damage) in the presence of product differentiation.

\section{The Model}

Consider a vertically differentiated market with two variants of the same good. Similarly to the models of vertical differentiation (Mussa and Rosen, 1978), the performance of the variant $i$, with $i=L, H$, determines its intrinsic or hedonic quality $q_{i}$. Accordingly, $q_{H}>q_{L}$ : variant $H$ has a higher intrinsic quality than variant $L$ so that $q_{H}$ is ranked higher along the hedonic quality ladder. Nevertheless, variant $q_{i}$ generates polluting emissions per unit of production at some level $e_{i}=\phi q_{i}$. Accordingly, variant $q_{H}$ represents the brown good. Conversely, variant $L$ is considered as green because its emissions $e_{L}$ are lower than those deriving from variant $q_{H}$, namely $e_{L}=\phi q_{L}<e_{H}$. The environmental quality of $L$ is then higher than that of $H$. The ranking between $q_{H}$ and $q_{L}$ is reversed when considered in terms of this latter dimension of quality: variant $q_{L}$ is ranked higher than variant $q_{H}$ along the environmental quality ladder. ${ }^{17}$ Assuming that either firm can produce only one type of product, intended as a combination of the two vertical attributes, captures the idea that it is costly and time-consuming for a firm to go green. ${ }^{18}$ For example, the switch to solar power requires the installation of solar panels on business facilities. Moreover, the cost reductions in energy savings are not always enough to counterbalance the conversion costs, at least in the short run. Therefore, it is reasonable to assume that the production choice is irreversible: either firm $i$ produces the variant $q_{i}$, corresponding to a given hedonic and environmental attributes. ${ }^{19}$

There is a continuum of consumers indexed by $\theta$ and uniformly distributed in the interval $[0, b]$ with density $1 / b$. Keeping the traditional interpretation from vertical differentiation models, parameter $\theta$ is proportional to the willingness to pay (henceforth WTP) for intrinsic quality, so that $b$ denotes the maximal WTP for the performance of a product among consumers. ${ }^{20}$ Formally, the

\footnotetext{
${ }^{17}$ It is worth noting that, from a social welfare viewpoint, the relative environmental quality of a variant does not play any role, being rather the absolute level of emissions, $e_{L}$ and $e_{H}$, the reference point of a social planner.

${ }^{18} \mathrm{We}$ also focus on the case in which firms produce different qualities so as to exclude that price competition leads to a Bertrand paradox.

${ }^{19} \mathrm{We}$ describe later the cost borne for going green. We relate this cost to cleaner technologies, thereby reinforcing the idea that the investment for being green is irreversible, at least in the short run.

${ }^{20}$ Under this assumption on density, the population of consumers is always constant. See Garcia-Gallego and Georgantzis (2009).
} 
indirect utility of consumer type $\theta$ writes as:

$$
U(\theta)=\left\{\begin{array}{c}
\theta q_{H}-p_{H}-\gamma\left(e_{H}-e_{L}\right), \text { if she buys the high quality good, } \\
\theta q_{L}-p_{L}+\gamma\left(e_{H}-e_{L}\right), \text { if she buys the low quality good, } \\
0, \text { if she refrains from buying. }
\end{array}\right.
$$

We add to the traditional component of the indirect utility function $\left(\theta q_{i}-p_{i}\right)$ a further ingredient, namely $\gamma\left(e_{H}-e_{L}\right)$ with $i \neq j$, such that the satisfaction of buying a product variant can be either amplified or decreased by the environmental characteristics of variant $i$ as compared with $j$. It is worth noting that it is not the level of emissions per se to determine the utility of consuming a variant. Rather, as both the green and the brown variant are intended as positional goods, it is the relative pollution emitted by them - captured by the term $\gamma\left(e_{H}-e_{L}\right)$ - to affect consumers' utility. ${ }^{21}$ Parameter $\gamma \geq 0$ measures the intensity of the relative dimension of consumption; ${ }^{22}$ the higher the value of $\gamma$, the stronger the relative (or social) preferences with respect to the hedonic ones. $^{23}$ For the sake of simplicity and without any loss of generality, we can assume that $\phi=1$, so that $\left(e_{H}-e_{L}\right)=\left(q_{H}-q_{L}\right) \cdot{ }^{24}$

From the above formulation of the utility function, the consumer that is indifferent between buying the low quality good and not buying at all is:

$$
\theta_{L}=\gamma+\frac{p_{L}-\gamma q_{H}}{q_{L}}=\frac{p_{L}-\gamma\left(q_{H}-q_{L}\right)}{q_{L}}
$$

with $\theta_{L}>0 \Longleftrightarrow p_{L}>\gamma\left(q_{H}-q_{L}\right)$. The consumer that is indifferent between buying the low quality good and the high quality good is:

$$
\theta_{H}=2 \gamma+\frac{p_{H}-p_{L}}{q_{H}-q_{L}}
$$

Thus, we immediately write the demand function faced by firm $i, x_{i}$ :

$$
\begin{aligned}
& x_{H}=\frac{1}{b}\left(b-\theta_{H}\right)=\frac{1}{b}\left[b-\left(2 \gamma+\frac{p_{H}-p_{L}}{q_{H}-q_{L}}\right)\right], \\
& x_{L}=\frac{1}{b}\left(\theta_{H}-\max \left\{\theta_{L}, 0\right\}\right)=\left\{\begin{array}{c}
\frac{1}{b}\left[\frac{p_{H} q_{L}-q_{H} p_{L}}{q_{L}\left(q_{H}-q_{L}\right)}+\frac{\gamma\left(q_{H}+q_{L}\right)}{q_{L}}\right] \text { if } \gamma<\frac{p_{L}}{q_{H}-q_{L}}, \\
\frac{1}{b}\left(2 \gamma+\frac{p_{H}-p_{L}}{q_{H}-q_{L}}\right) \text { if } \gamma \geq \frac{p_{L}}{q_{H}-q_{L}} .
\end{array}\right.
\end{aligned}
$$

Note that, as soon as $\theta_{L}$ is not positive, the market is covered, that is also consumer type $\theta=0$ is willing to buy.

\footnotetext{
${ }^{21}$ See Ben Elhadi et al. (2015) for an in-depth discussion of this formalization. An alternative way to model the utility function would be relating the satisfaction of an individual when consuming a hedonic quality variant with its absolute environmental quality. In this latter formulation however, the status or positional content of green consumption would not be captured. We discuss in Section 5 the main property of the model under this alternative utility function.

${ }^{22}$ In our work, we use the terms social and relative interchangeably given that they both indicate that consumption has a social dimension. Likewise, the resulting satisfaction also depends on the characteristics of society.

${ }^{23}$ The extreme case $\gamma=0$ reduces the model to the traditional vertical differentiation framework with hedonic preferences as unique drivers for consumption.

${ }^{24}$ We could consider a generic $\phi>0$ without normalizing $\phi$ to 1 . However, this would not bring any further insight to the model while making the analysis extremely cumbersome.
} 
It is easy to see that the defining property of vertical differentiation can cease to hold in this setting. In particular, when $q_{H}$ and $q_{L}$ are sold at the same price, the demand functions are:

$$
\begin{aligned}
\left.x_{H}\right|_{p_{H}=p_{L}} & =\frac{1}{b}(b-2 \gamma), \\
\left.x_{L}\right|_{p_{H}=p_{L}} & =\left\{\begin{array}{c}
\frac{1}{b}\left[\frac{\gamma\left(q_{H}+q_{L}\right)-p_{L}}{q_{L}}\right] \text { if } \gamma<\frac{p_{L}}{q_{H}-q_{L}}, \\
\frac{2 \gamma}{b} \text { if } \gamma \geq \frac{p_{L}}{q_{H}-q_{L}} .
\end{array}\right.
\end{aligned}
$$

Notice that:

$$
\begin{aligned}
&\left.x_{H}\right|_{p_{H}=p_{L}}>0 \Longleftrightarrow \gamma<\frac{b}{2} \equiv \gamma^{H}, \\
&\left.x_{L}\right|_{p_{H}=p_{L}}>0 \Longleftrightarrow\left\{\begin{array}{c}
\gamma>\frac{p_{L}}{q_{H}+q_{L}} \equiv \gamma^{L}\left(p_{L}\right) \text { if } \gamma<\frac{p_{L}}{q_{H}-q_{L}} \\
\forall \gamma>0 \text { if } \gamma \geq \frac{p_{L}}{q_{H}-q_{L}},
\end{array}\right.
\end{aligned}
$$

with $\frac{p_{L}}{q_{H}-q_{L}}>\gamma^{L}\left(p_{L}\right)$. It follows that the market is characterized by vertical differentiation for extreme values of $\gamma$, namely either $\gamma \leq \min \left\{\gamma^{L}\left(p_{L}\right), \gamma^{H}\right\}$ or $\gamma \geq \max \left\{\gamma^{L}\left(p_{L}\right), \gamma^{H}\right\}$. In the former case, the environmental awareness is not very significant and no consumer would be willing to buy the green good if its price was equal to that of the brown alternative. The performance of a product defining its hedonic quality dominates the environmental impact which describes its environmental quality and we are in hedonic vertical differentiation. On the contrary, in the latter case, consumers' involvement in environmental protection is so strong that, even if prices coincide, no one would buy the brown good, in spite of its better performance. The environmental dimension of quality dominates the hedonic dimension and we observe environmental vertical differentiation. Finally, for intermediate values of $\gamma$, namely $\gamma \in\left(\min \left\{\gamma^{L}\left(p_{L}\right), \gamma^{H}\right\}, \max \left\{\gamma^{L}\left(p_{L}\right), \gamma^{H}\right\}\right)$, both firms may obtain a positive market share when they sell at the same price, and horizontal differentiation turns out to be the proper way to describe the competition between firms. In particular, this happens when $b \geq b_{D}\left(p_{L}\right)$, with

$$
b_{D}\left(p_{L}\right) \equiv \frac{2 p_{L}}{\left(q_{H}+q_{L}\right)} .
$$

On the contrary, when $b \in\left(0, b_{D}\left(p_{L}\right)\right)$, in $\gamma \in\left(\gamma^{H}, \gamma^{L}\left(p_{L}\right)\right)$ neither firm has a positive demand when they charge the same price. ${ }^{25}$

We can summarize the above findings in the following Proposition:

Proposition 1 For extreme values of $\gamma$, namely either $\gamma \leq \min \left\{\gamma^{L}\left(p_{L}\right), \gamma^{H}\right\}$ or $\gamma \geq \max \left\{\gamma^{L}\left(p_{L}\right), \gamma^{H}\right\}$, the defining property of vertical differentiation holds. In the former (resp. the latter) case, the hedonic quality dimension (resp. the environmental quality dimension) is the main driver of consumption.

\footnotetext{
${ }^{25}$ Formally $b \geq b_{D}\left(p_{L}\right)$ ensures that $\gamma^{H}>\gamma_{L}\left(p_{L}\right)$.
} 
We assume that profit functions of firms $H$ and $L$ respectively write as:

$$
\begin{aligned}
\pi_{H} & =x_{H} \cdot p_{H}, \\
\pi_{L} & =\left(p_{L}-c\right) x_{L},
\end{aligned}
$$

where $c>0$ is the cost per unit of green production. In the above formulation, production costs for firms only come from producing an environmentally friendly good. Otherwise, one could imagine that there exists a cost function $c_{i}=h_{i}+E_{i}$ where $h_{i}$ denotes the hedonic-quality specific cost borne by firm $i$, with $h_{H}>h_{L}$ and $E_{i}$ the environmental quality specific cost, with $E_{H}<E_{L} \cdot{ }^{26}$ Since it is reasonable that $h_{H}>h_{L}$ always holds, the only way to get $c_{H}<c_{L}$ is to assume that $\left(E_{L}-E_{H}\right)>\left(h_{H}-h_{L}\right)$. Without loss of generality, we can write $c_{L}>c_{H}=0 .{ }^{27}$

In the following analysis we show that different market equilibrium configurations may arise, depending on the parameters' values, focusing in particular on the interplay between $b$ and $\gamma$. In order to solve the model, we will compute the price equilibrium candidates corresponding to each market configuration and provide the parametric intervals for which they yield the corresponding market outcomes. ${ }^{28}$ In the text we limit the analysis to the case where the quality gap is such that $q_{H} / q_{L} \in(1,2)$. In the Appendix, we provide the complementary analysis where $q_{H} / q_{L} \geq 2$ and show there that our qualitative findings are robust to this extension.

\section{The equilibrium analysis}

Typically, in a vertically differentiated setting, in absence of production costs, there is always room for two firms if the market is not a natural duopoly. ${ }^{29}$ Furthermore, when the lowest WTP in the market is equal to zero, firms never find it profitable to cover the market. Accordingly, the starting point of our analysis is that both firms are active and the market is uncovered. Therefore, demands are defined as $x_{L}=\left(\theta_{H}-\theta_{L}\right) / b$ and $x_{H}=\left(b-\theta_{H}\right) / b$, and profit functions are given by (4) and (5). The pair of candidate equilibrium prices can be easily obtained:

$$
\begin{aligned}
p_{L}^{*} & =\frac{2 c q_{H}+\left(q_{H}-q_{L}\right)\left(2 \gamma q_{H}+b q_{L}\right)}{4 q_{H}-q_{L}}, \\
p_{H}^{*} & =\frac{c q_{H}+\left(q_{H}-q_{L}\right)\left[2 b q_{H}-\gamma\left(3 q_{H}-q_{L}\right)\right]}{4 q_{H}-q_{L}} .
\end{aligned}
$$

\footnotetext{
${ }^{26}$ The case $c_{H}>c_{L}$ has been largely treated in the literature on vertical differentiation. Thus, we can disregard it.

${ }^{27}$ One may wonder why we do not introduce some fixed costs to capture the role of green technologies in production. Admittedly, when the quality is mainly related to investments in new technologies or in R\&D, the assumption of fixed quality-specific costs can be reasonable. Nevertheless, a fixed cost does not affect the price game as it does not alter firms' best reply functions. In Section 5 we consider alternative cost specifications, such as a marginal cost increasing with the level of greenness and a fixed cost of greenness, in order to prove the robustness of our results.

${ }^{28}$ This is standard in models of vertical differentiation. See Wauthy (1996) for more details.

${ }^{29}$ The upper bound to the number of firms which can coexist at equilibrium with positive market share and positive equilibrium prices has nothing to do with costs and only depends on pattern of tastes and willingness to pay distribution. In particular, given a population of consumers, identified by the parameter $\theta \in[\alpha, \beta], 0 \leq \alpha<\beta$, the upper bound to the number of firms is 2 so that the market is a natural duopoly iff $\frac{\alpha}{\beta} \in\left[\frac{1}{4}, \frac{1}{2}\right]$.
} 
Formally, for this candidate to be an equilibrium, we need to verify that both prices are positive and that $p_{L}$ is higher than the marginal cost, namely $p_{L}^{*}>c$ and $p_{H}^{*}>0$ :

$$
\begin{aligned}
& p_{L}^{*} \geq c \Longleftrightarrow \gamma \geq \frac{c\left(2 q_{H}-q_{L}\right)-b q_{L}\left(q_{H}-q_{L}\right)}{2 q_{H}\left(q_{H}-q_{L}\right)} \equiv \underline{\gamma}, \\
& p_{H}^{*} \geq 0 \Longleftrightarrow \gamma \leq \frac{q_{H}\left[2 b\left(q_{H}-q_{L}\right)+c\right]}{\left(q_{L}-3 q_{H}\right)\left(q_{L}-q_{H}\right)} \equiv \bar{\gamma},
\end{aligned}
$$

with

$$
\begin{aligned}
& \underline{\gamma}>0 \Longleftrightarrow b<b_{0} \equiv \frac{c\left(2 q_{H}-q_{L}\right)}{q_{L}\left(q_{H}-q_{L}\right)}, \\
& \bar{\gamma}>\underline{\gamma} \Longleftrightarrow b>\underline{b} \equiv \frac{c}{\left(q_{H}+q_{L}\right)},
\end{aligned}
$$

and $b_{0}>\underline{b}$. Moreover, we have to demonstrate that the market is uncovered, and that both goods have positive demands, i.e. $0<\theta_{L}<\theta_{H}<$ b. By plugging (6) and (7) into (1) and (2), we obtain:

$$
\begin{aligned}
& \theta_{H}^{*} \leq b \Longleftrightarrow \gamma \leq \bar{\gamma}, \theta_{L}^{*} \leq \theta_{H}^{*} \Longleftrightarrow \gamma \geq \underline{\gamma}, \\
& \theta_{L}^{*} \geq 0 \Longleftrightarrow \gamma \leq \hat{\gamma} \equiv \frac{2 c q_{H}+b\left(q_{H}-q_{L}\right) q_{L}}{\left(2 q_{H}-q_{L}\right)\left(q_{H}-q_{L}\right)},
\end{aligned}
$$

where the precise values of $\theta_{L}^{*}$ and $\theta_{H}^{*}$ are reported in the Appendix (see the Proof of Lemma 1). Moreover:

$$
\widehat{\gamma}>\bar{\gamma} \Longleftrightarrow b<\widehat{b} \equiv \frac{c q_{H}}{\left(q_{H}-q_{L}\right)^{2}} .
$$

One can already notice that there are situations where an interior duopoly solution with uncovered market cannot be sustained at equilibrium. For example, when $\gamma>\bar{\gamma}, \theta_{H}^{*}>b$ (and $p_{H}^{*}<0$ ), then firm $H$ cannot be active at the duopoly equilibrium. Moreover, in the parametric region where $b>\widehat{b}$ and $\gamma>\widehat{\gamma}, \theta_{L}^{*}<0$ then the market is covered. In particular, in this latter case of duopoly covered at the limit, the pair of candidate equilibrium prices is:

$$
\begin{aligned}
p_{L}^{C} & =\gamma\left(q_{H}-q_{L}\right), \\
p_{H}^{C} & =\frac{(b-\gamma)\left(q_{H}-q_{L}\right)}{2}
\end{aligned}
$$

where additional superscript $C$ indicates the covered market. ${ }^{30}$

The following lemmas identify the market configurations that emerge for each combination of $b$ and $\gamma$, the crucial parameters of our model. We include the mathematical proofs in the Appendix. Lemma 1 specifies the conditions for the duopoly equilibrium to hold:

\footnotetext{
${ }^{30}$ In the Appendix we provide further insights and additional calculations for this and following cases. See also the corresponding Lemmas for further details on the precise parametric regions where such price candidates hold at equilibrium.
} 
Lemma 1 Provided $b>\underline{b}$, both firms are active in the market when $\gamma \in[\max \{0, \underline{\gamma}\}, \max \{\bar{\gamma}, b\})$. The duopoly is sustained by an interior equilibrium for $\gamma \in[\max \{0, \underline{\gamma}\}, \min \{\bar{\gamma}, \hat{\gamma}\})$, while it is sustained by a corner equilibrium with market coverage for $\gamma \in[\widehat{\gamma}, b)$. The latter possibility only occurs when $b \geq \widehat{b}$.

Proof. See Appendix.

It follows that, when $b$ is sufficiently high and $\gamma$ is not excessive, a duopoly emerges at the equilibrium. When this happens, two additional results are worthy of attention. First, by comparing equilibrium prices in the duopoly scenarios, we find that:

Remark 1 When the market is characterized by a duopoly, the equilibrium price of the green variant can be higher than that of the brown variant. In particular, this always holds when the duopoly is covered at the limit, and in $\gamma \in(\widetilde{\gamma}, \min \{\bar{\gamma}, \hat{\gamma}\})$ when the duopoly is uncovered, given that $p_{L}^{*}>p_{H}^{*}$ when $\gamma>\frac{b\left(2 q_{H}^{2}-3 q_{H} q_{L}+q_{L}^{2}\right)-c q_{H}}{\left(q_{H}-q_{L}\right)\left(5 q_{H}-q_{L}\right)} \equiv \widetilde{\gamma}$.

Proof. See Appendix.

Second, by recalling Proposition 1, we find that:

Remark 2 For intermediate values of $\gamma$ the duopoly equilibrium is characterized by horizontal differentiation and both firms get a positive market share when selling at the same price. For relatively high (low) values of $\gamma$, environmental (hedonic) vertical differentiation prevails.

Proof. See Appendix.

By combining the results of Lemma 1 and Remarks 1-2, one realizes how the duopoly equilibrium is crucially affected by social preferences. For relatively low levels of $\gamma$, hedonic vertical differentiation characterizes the market interaction between the brown and the green producer. Consumers are mainly interested in the intrinsic quality of the product rather than its environmental impact, and the brown firm can charge a higher price than its green rival. For intermediate values of $\gamma$, horizontal differentiation prevails and both producers obtain a positive market share even when charging the same price. Within this parametric region, a price switch occurs for $\gamma>\widetilde{\gamma}$, meaning that the green producer obtains a price premium since environmental savvy consumers highly value the green dimension of quality. Such a price gain is more pronounced when $\gamma$ further increases. Moreover, as we enter the interval region $\gamma>\gamma^{H}$, environmental vertical differentiation properly describes market competition, as we know from Proposition 1. In the last region compatible with a duopoly equilibrium, i.e. $\gamma \in[\widehat{\gamma}, b)$, not only the green producer enjoys the price premium, but it also covers the market at the limit.

In order to complete the characterization of the market equilibria, we next consider the possibility for either firm to monopolize the market. In case of green monopoly, the candidate equilibrium price 
for the covered market coincides with $p_{L}^{C}$ defined in (12), while for the uncovered market it is:

$$
p_{L}^{M}=\frac{c+\gamma\left(q_{H}-q_{L}\right)+b q_{L}}{2}
$$

where $M$ indicates the monopoly case. As for the brown monopoly, the candidate equilibrium price is

$$
p_{H}^{M}=\frac{b q_{H}-\gamma\left(q_{H}-q_{L}\right)}{2} .
$$

Our results are gathered in Lemmas 2 and 3.

Lemma 2 The green firm monopolizes the market for $\gamma>\max \left\{\underline{\gamma}^{M}, \bar{\gamma}, b\right\}$, where $\underline{\gamma}^{M} \equiv \frac{c-b q_{L}}{q_{H}-q_{L}}$. The green monopoly market is covered for $\gamma \geq \gamma^{M} \equiv \frac{c+b q_{L}}{q_{H}-q_{L}}$, otherwise it remains uncovered.

Proof. See Appendix.

Lemma 3 The brown firm monopolizes the market in the range of parameters such that $b \in\left[0, b_{0}\right)$ and $\gamma<\min \left\{\underline{\gamma}, \bar{\gamma}^{M}\right\}$, where $\bar{\gamma}^{M} \equiv \frac{b q_{H}}{\left(q_{H}-q_{L}\right)}$.

Proof. See Appendix.

Finally, we can identify a relatively small interval region where neither the brown nor the green producer is active on the market. In particular,

Lemma 4 There is no active firm at the market equilibrium when $b \in[0, \underline{b})$ and $\gamma \in\left(\bar{\gamma}^{M}, \underline{\gamma}^{M}\right)$.

Proof. See Appendix.

While the results of Lemma 4 complete our equilibrium analysis, we focus on intervals where at least one firm is active. The following Proposition summarizes the main findings of Lemmata (1-3):

Proposition 2 Depending on the interplay between $b$ and $\gamma$, we can characterize two relevant parametric regions:

(i) For relatively low values of $b(b \in(\underline{b}, \widehat{b}))$, both firms are active at the interior equilibrium when $\gamma$ takes intermediate values, while the market is monopolized by the green (resp. brown) producer for $\gamma$ sufficiently high (resp. low). At the green monopoly equilibrium, the green producer finds it profitable to cover the whole market when $\gamma$ is extremely relevant.

(ii) When $b$ is relatively high $(b \geq \widehat{b})$, the brown producer never monopolizes the market. Further, under duopoly, the green firm can optimally cover the market. This happens when $\gamma$ is relatively high. Finally, it becomes increasingly difficult for the green firm to monopolize the market. 
Proof. It directly follows from combining the proofs of Lemmata 1-3.

Figure 1 represents all the different market configurations which emerge at equilibrium, together with the price switch discussed in Remark $1 .{ }^{31}$ As we restricted our attention to the case $q_{H} / q_{L} \in$ $[1,2)$, Figure 1 is plotted by fixing $q_{H}=1.5$ and $q_{L}=1$, together with $c=1$. This is without loss of generality. ${ }^{32}$ Given that we focused only on market prices in the previous analysis, Table 1 provides the corresponding market shares and profits.

Figure 1: $q_{H} / q_{L} \in(1,2)$

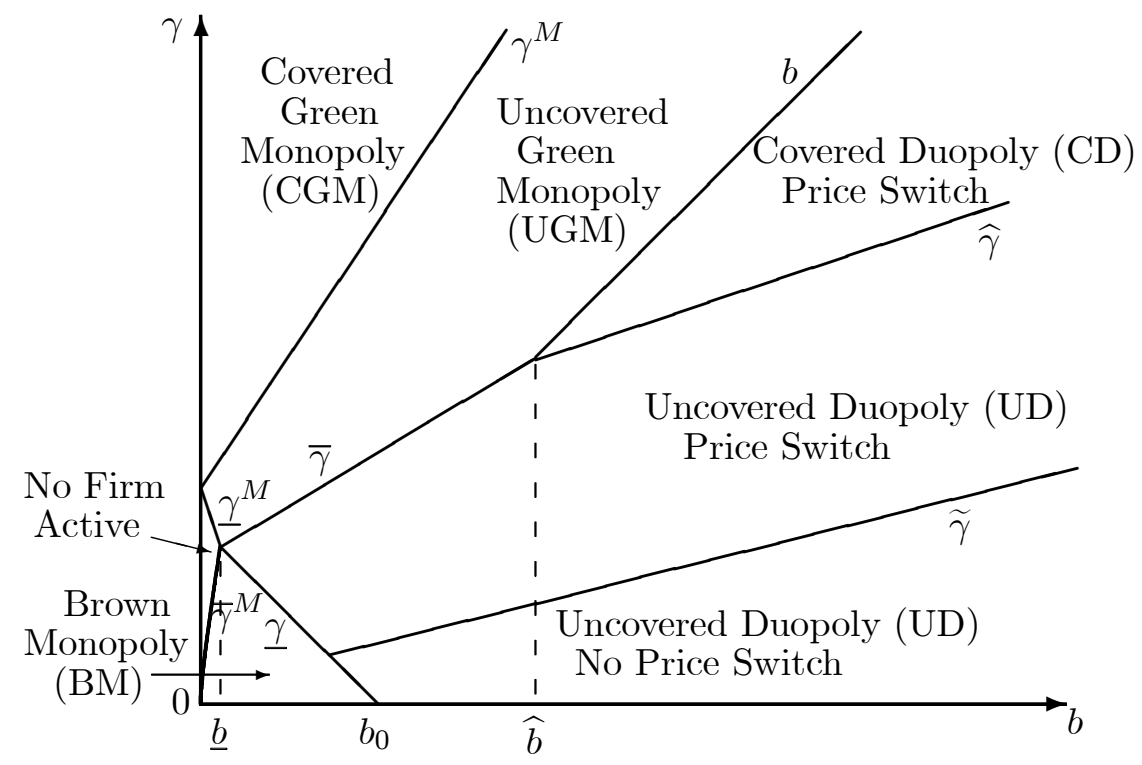

Table 1

\begin{tabular}{|l|l|l|}
\hline & Market share & Profits \\
\hline \multirow{2}{*}{$\mathrm{UD}$} & $x_{L}^{*}=\frac{q_{H}\left[\left(q_{H}-q_{L}\right)\left(2 \gamma q_{H}+b q_{L}\right)-c\left(2 q_{H}-q_{L}\right)\right]}{b q_{L}\left(4 q_{H}-q_{L}\right)\left(q_{H}-q_{L}\right)}$, & $\pi_{L}^{*}=\frac{q_{H}\left[\left(q_{H}-q_{L}\right)\left(2 \gamma q_{H}+b q_{L}\right)-c\left(2 q_{H}-q_{L}\right)\right]^{2}}{b q_{L}\left(q_{H}-q_{L}\right)\left(4 q_{H}-q_{L}\right)^{2}}$, \\
& $x_{H}^{*}=\frac{c q_{H}+\left(q_{H}-q_{L}\right)\left[2 b q_{H}-\gamma\left(3 q_{H}-q_{L}\right)\right]}{b\left(4 q_{H}-q_{L}\right)\left(q_{H}-q_{L}\right)}$ & $\pi_{H}^{*}=\frac{\left\{c q_{H}+\left(q_{H}-q_{L}\right)\left[2 b q_{H}-\gamma\left(3 q_{H}-q_{L}\right)\right]\right\}^{2}}{b\left(q_{H}-q_{L}\right)\left(4 q_{H}-q_{L}\right)^{2}}$. \\
\hline \multirow{2}{*}{$\mathrm{CD}$} & $x_{L}^{C}=\frac{(b+\gamma)}{2 b}$, & $\pi_{L}^{C}=\frac{(b+\gamma)\left[\gamma\left(q_{H}-q_{L}\right)-c\right]}{2 b}$, \\
& $x_{H}^{C}=\frac{(b-\gamma)}{2 b}$. & $\pi_{H}^{C}=\frac{(b-\gamma)^{2}\left(q_{H}-q_{L}\right)}{4 b}$. \\
\hline $\mathrm{UGM}$ & $x_{L}^{M}=\frac{\gamma\left(q_{H}-q_{L}\right)-c+b q_{L}}{2 b q_{L}}$. & $\pi_{L}^{M}=\frac{\left[c-b q_{L}-\gamma\left(q_{H}-q_{L}\right)\right]^{2}}{4 b q_{L}}$. \\
\hline $\mathrm{CGM}$ & $x_{L}^{C M}=1$ & $\pi_{L}^{C M}=\gamma\left(q_{H}-q_{L}\right)-c$ \\
\hline $\mathrm{BM}$ & $x_{H}^{M}=\frac{b q_{H}-\gamma\left(q_{H}-q_{L}\right)}{2 b q_{H}}$ & $\pi_{H}^{M}=\frac{\left[b q_{H}-\gamma\left(q_{H}-q_{L}\right)\right]^{2}}{4 b q_{H}}$ \\
\hline
\end{tabular}

$\mathrm{UD}=$ Uncovered duopoly, $\mathrm{CD}=$ Covered duopoly, $\mathrm{UGM}=$ Uncovered green monopoly, $\mathrm{CGM}=$ Covered green monopoly, $\mathrm{BM}=$ Brown monopoly

It is interesting to consider how profits in the different market configurations change with $b$,

\footnotetext{
${ }^{31}$ The issue of vertical vs. horizontal differentiation reported in Remark 2, while being useful in interpreting our results, does not add much in terms of graphical representation.

${ }^{32}$ As we already mentioned, we provide the analytical solutions of the case $q_{H} / q_{L} \geq 2$ in the Appendix.
} 
namely the highest willingness to pay for the hedonic quality. ${ }^{33}$ To this aim, first notice that the equilibrium prices always increase in $b$. This result is general (since it holds whatever the equilibrium configuration) and intuitive: as $b$ increases, consumers' willingness to pay for quality increases, and in turn equilibrium prices increase. Nonetheless, equilibrium profits are not always increasing in $b$. In particular, while the equilibrium profits of the brown firm increase in $b$ for any value of $\gamma$, those of the green firm may either increase or decrease, depending on the equilibrium configuration. This crucially depends on the impact of $b$ on the equilibrium market share of the green firm. Figure 2 highlights this finding.

Figure 2: $\partial \pi_{L} / \partial b$ in $q_{H} / q_{L} \in(1,2)$

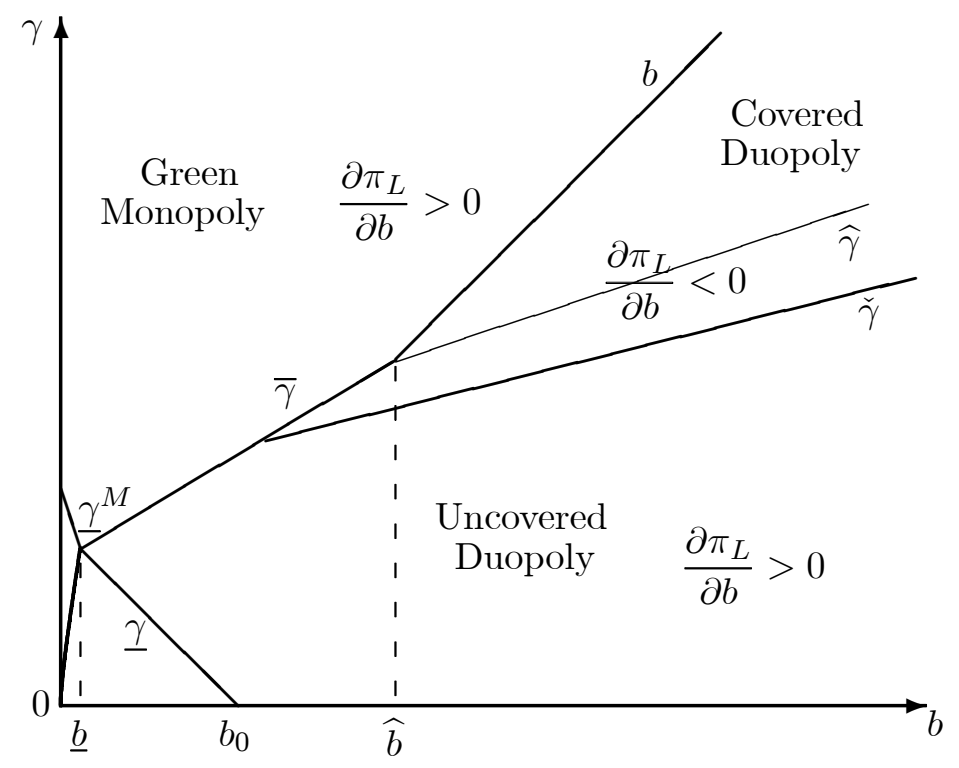

At the monopoly equilibria, not only the equilibrium price but also the corresponding market share increases with the consumers' willingness to pay. This explains why the green firm's profits are increasing in $b$. On the contrary, at the duopoly equilibrium, they increase with $b$ only when $\gamma$ is sufficiently low, namely $\partial \pi_{L} / \partial b>0$ when $\gamma<\check{\gamma}$ in Figure $2 .{ }^{34}$ In order to get an intuition for this result, it is useful to go through the equilibrium demands in the case of duopoly. For low values of $\gamma$, when the market is uncovered, the model behaves as in a traditional setting of (hedonic) vertical differentiation (that is the case $\gamma \rightarrow 0$ ). In particular, an increase of $b$ implies that both equilibrium prices increase, with $p_{H}$ increasing more than $p_{L}$. This in turn involves that equilibrium demand for the brown high quality firm decreases, whereas the one for the green low quality firm increases. Indeed, the green firm gains more consumers "at the right-end" (at the expenses of the brown firm) than those which loses "at the left-end" of the market (as its equilibrium price increases). Hence, both

\footnotetext{
${ }^{33}$ We include in the Appendix (Profits at the duopoly equilibrium: the role of $b$ and $\gamma$ ) the analytical computations of the effect of $b$ and $\gamma$ on equilibrium market shares and profits.

${ }^{34}$ The threshold value $\check{\gamma}$ can be found in the Appendix.
} 
the equilibrium price and the corresponding market share increase in $b$, thus explaining the resulting increase in profits. As for the brown firm, the price surge overcomes the demand contraction so that its profits increase as well. At the other extreme, when $\gamma$ is sufficiently high to outweigh the hedonic attribute, thus inverting the quality ranking, vertical environmental differentiation prevails. This is the reason why $\partial x_{L}^{*} / \partial b<0$ and $\partial x_{H}^{*} / \partial b>0$; the equilibrium demand of the green good (which is considered now of high quality) decreases, whereas the demand of the brown good (which is perceived of low quality) increases. When $\gamma$ is very high $(\gamma>\check{\gamma}$ in Figure 2$)$, the demand reduction suffered by the green producer prevails over the price increase, thus explaining why $\partial \pi_{L}^{*} / \partial b<0$. This result applies a fortiori in the case of the corner duopoly, where the equilibrium market share of the green firm decreases with $b$, whereas its equilibrium price is independent of $b$.

Corollary 1 Consider the green firm. When it enjoys a monopoly position at the equilibrium, its profits increase with $b$. At the duopoly equilibria, its profits increase with $b$ whenever the social component of consumption $\gamma$ is not extremely significant. On the contrary, they decrease in $b$ when $\gamma$ is sufficiently high, as the demand reduction prevails over the price increase.

As far as the effect of the social component of consumption is concerned, whatever the equilibrium configuration, an increment of $\gamma$ always benefits the green firm while damaging the brown one given $b$. Notice that, although the impact of $\gamma$ on the equilibrium profits is intuitive, it crucially contributes to determine the market configuration prevailing at equilibrium, given $b$. Consider sufficiently high values of $b(b>\underline{b})$ and $\gamma(\gamma>\underline{\gamma})$ and focus on Lemmas 1 and 2, combined with Remarks 1 and 2. Figure 1 shows that the duopoly holds at equilibrium when $\gamma \in[\max \{0, \gamma\}, \max \{\bar{\gamma}, b\}$ ), as from Lemma 1. Indeed, it shows the interval region where the price switch takes place $(\gamma>\widetilde{\gamma}$, as from Remark 1) and the green firm can quote a price higher than the brown rival, its variant being perceived higher than the other along the quality ladder. In this case, the environmental dimension of quality is more valuable than the hedonic counterpart, and we can even have a region characterized by environmental vertical differentiation (Remark 2 ).

Another interesting feature of our model is that both the price of the green variant and the corresponding market share increase with $\gamma$, whatever the equilibrium market configuration. ${ }^{35}$ Accordingly, there is no trade-off between the price switch and the market share enjoyed by the green firm. In fact, for sufficiently high values of $\gamma$, the brown firm stays inactive. This is represented in Figure 1 in the parametric region $\gamma>\max \left\{\underline{\gamma}^{M}, \bar{\gamma}, b\right\}$, where the green firm monopolizes the market, as we know from Lemma 2. Finally, for extremely high values of $\gamma\left(\gamma \geq \gamma^{M}\right)$, the market is covered and the green firm sells its variant to the whole set of consumers.

\footnotetext{
${ }^{35}$ Indeed, the positive effect of $\gamma$ on the equilibrium price and market share is observed under both duopoly and monopoly.
} 
Notice that these results are always mitigated by parameter $b$. This is evident in Figure 1, where, the higher the $b$, the higher the $\gamma-$ value required for the above results to emerge. Therefore, we can state:

Corollary 2 Ceteris paribus, both the price switch and the green monopolization results are more likely to occur for relatively low values of $b$.

Proof. It is relatively easy to show that all the relevant threshold values of $\gamma$ are increasing in $b$. This, combined with the proofs of Lemmata 1-3, completes the demonstration.

Finally, the above results can be applied to each specification of the quality ratio $q_{H} / q_{L}$. The equilibrium analysis reported in this section assumes a quality gap such that $q_{H} / q_{L} \in(1,2)$. In the Appendix we show that the same qualitative results hold for $q_{H} / q_{L} \geq 2$; although the interval region defined by the relevant threshold values of $\gamma$ change in dimension, at equilibrium we get the same market configurations as in Proposition 2. Figure 3 represents this case. The unique difference with respect to Figure 1 is that $q_{H}=2.8$.

Figure 3: $q_{H} / q_{L} \geq 2$

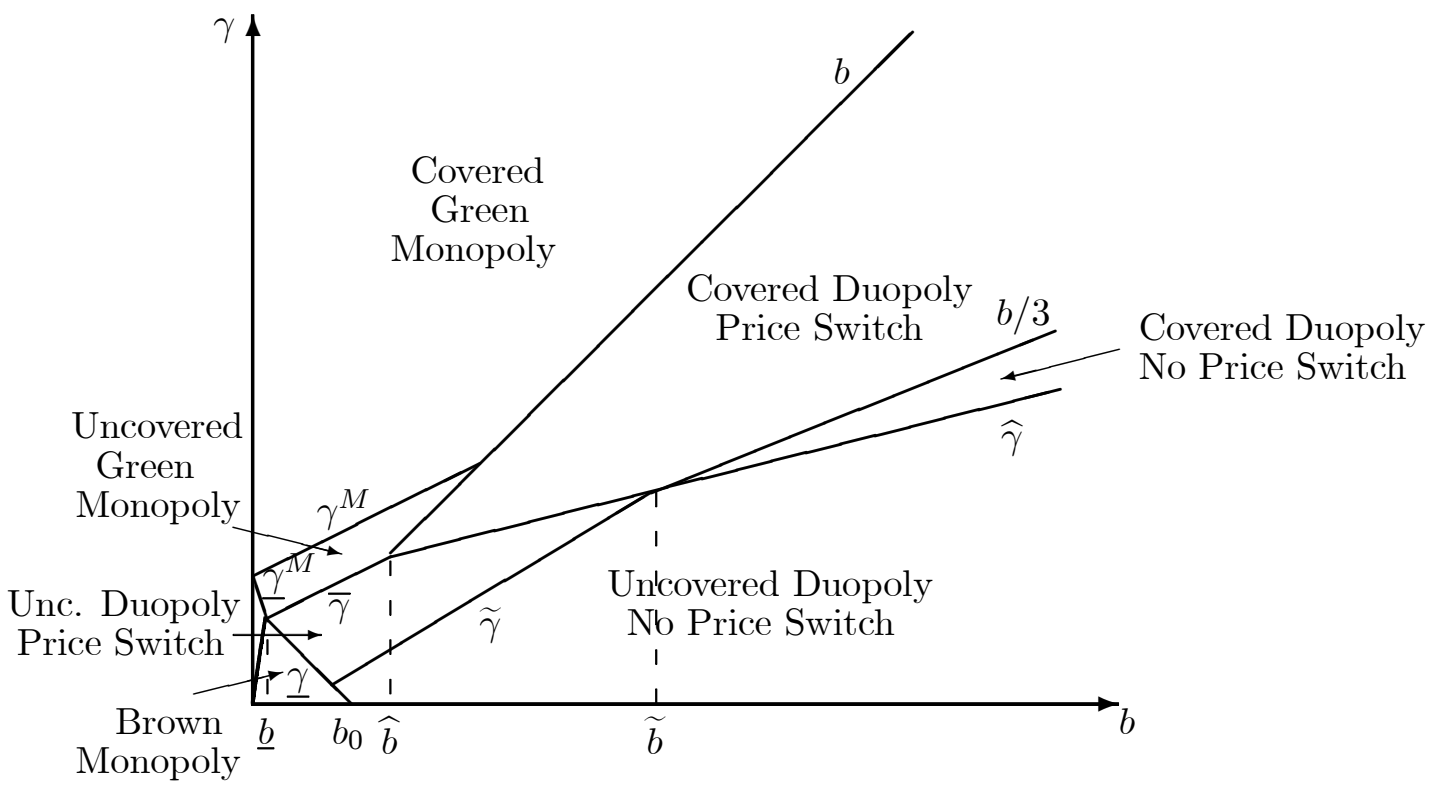

A comparison between Figure 1 and Figure 3 enables us to evaluate the consequences of increasing the quality gap between the two variants. Two forces are pushing towards opposite directions given that consumers value the environmental performance of the product and not only its intrinsic quality. On the one hand, as $q_{H} / q_{L}$ increases, consumers appreciate the intrinsic quality difference more, thus rewarding the high quality-brown producer. On the other hand, the higher hedonic quality gap, which corresponds to a higher environmental quality gap, raises the social component of consumption $\gamma\left(q_{H}-q_{L}\right)$, thus contributing to favor the low quality-green producer. It is again the interaction between $\gamma$ and $b$ that determines which of these two forces dominates. When $\gamma$ is relatively high, 
notice in Figure 3 that the area where the market is covered, both for the green monopoly and for the duopoly, expands. Ceteris paribus, an increase in the quality gap is reflected here in a higher effectiveness of relative preferences. On the contrary, for relatively low levels of $\gamma$, the intrinsic quality dominates the environmental effects, and an increase in $q_{H} / q_{L}$ benefits the brown producer. One can notice, for example, that the area where the price switch does not occur is larger in Figure $3{ }^{36}$

\section{Some environmental policy implications}

We evaluate the effect on the environmental damage of imposing a minimum quality standard (MQS) on pollution emissions. We assume that the MQS is binding only for the brown firm, which is induced to improve its environmental quality (i.e. to reduce $q_{H}$ ), while the green firm does not change its quality variant. ${ }^{37}$ We consider the case in which the brown firm still pollutes more than the green rival (namely $e_{H}>e_{L}$ ). Moreover, the abatement effort penalizes the intrinsic quality of a good so that a trade-off between environmental quality and hedonic quality immediately emerges. ${ }^{38}$ The total environmental damage deriving from global emissions $(D)$ is defined as the sum of the environmental damage coming from both the green and the brown firm, respectively indicated as $D^{L}=q_{L} x_{L}$ and $D^{H}=q_{H} x_{H} \cdot{ }^{39}$ Remember that we previously assumed that hedonic qualities reflect the per-unit emissions of the goods, i.e. $q_{L}=e_{L}$ and $q_{H}=e_{H}$. Formally, we consider how $D^{L}$ and $D^{H}$ change with $q_{H}$ for any given $q_{L}$.

The main findings can be explained by tracking down a technique effect and a stealing effect which appears when the environmental quality gap diminishes. The former indicates the direct reduction in the total damage deriving from the abatement effort which reduces pollution emissions per unit of output. The latter captures the indirect increase in total damage due to the expansion of the brown firm's market share at the expense of the green rival. In our model, the stealing effect is moved by two drivers: a price competition driver and a social component driver. Improving the environmental quality of the brown good reduces the quality gap between variants, thereby reinforcing the price competition driver. As a result, the brown firm expands its market share and steals consumers from the rival. An immediate consequence is a reduction of the damage coming from the green firm, $D^{L}$. As for $D^{H}$, the overall effect is ambiguous. This stealing effect is magnified by the social driver $\gamma$ while weakened by the WTP for the hedonic quality $b$. The higher is $\gamma$, and/or the lower is $b$, the larger the market share obtained by the brown producer due to the quality gap reduction. Thus, for a relatively high $\gamma$, the social component of consumption reinforces price competition so that $D^{H}$ increases. Rather, as long as $\gamma$ is low relative to $b$, the stealing effect is not very strong due to the

\footnotetext{
${ }^{36} \mathrm{An}$ increase in $q_{H} / q_{L}$ implies an upward shift of $\widetilde{\gamma}$, as it can be easily demonstrated.

${ }^{37}$ We briefly discuss the possibility for this MQS to be binding for both firms at the end of this section.

${ }^{38}$ This holds at least in the short-run, and we confine our analysis to this case.

${ }^{39}$ The environmental damage is usually taken to be quadratic in the level of emissions. This alternative assumption would not change our qualitative results. Indeed, $\partial D^{2} / \partial q_{H}=2 D\left(\partial D / \partial q_{H}\right)$, so that given the positiveness of $D$, the sign of $\partial D^{2} / \partial q_{H}$ coincides with the sign of $\partial D / \partial q_{H}$. See also Lambertini (2013) for this assumption of linear damage.
} 
weakness of the social driver and the technique effect can prevail with a corresponding reduction in $D^{H}$.

The intensities of these contrasting forces depend on the market configuration that emerges at equilibrium. Indeed, in case of uncovered duopoly, the environmental damage is:

$$
D_{D}=D_{D}^{L}+D_{D}^{H}=q_{H} \frac{b\left(2 q_{H}+q_{L}\right)+\gamma\left(q_{L}-q_{H}\right)-c}{\left(4 q_{H}-q_{L}\right)} .
$$

A reduction of $q_{H}$ raises the equilibrium market share of the brown firm while decreasing that of the green producer when $\gamma$ is sufficiently high, as the consumption coming from the social motivation decreases when the environmental quality gap diminishes. ${ }^{40}$ In this case, the brown firm expands its market share by stealing consumers from the rival. Thus, the damage coming from the output produced by the green firm $\left(D_{D}^{L}\right)$ decreases. As for the effect on the damage deriving from the production of the brown firm, this is ambiguous. On the one hand, per unit emissions decrease (technique effect), but on the other hand, the market share of the brown firm increases (stealing effect). The first effect is independent of $\gamma$ and $b$. The second effect increases instead with $\gamma$ and decreases with $b$. As a result, as long as $\gamma$ is low relative to $b$, the direct effect of reducing $q_{H}$ predominates, so that $D_{D}^{H}$ diminishes, and therefore total damage decreases. In contrast, for higher values of $\gamma$, it is the indirect effect to prevail so that $D_{D}^{H}$ increases. For very high values of $\gamma$, the increase in $D_{D}^{H}$ is stronger than the reduction in $D_{D}^{L}$, and total damage augments. All in all, the overall effect of reducing $q_{H}$ is such that the total damage increases for relatively high values of $\gamma$ whereas it decreases in the opposite case.

Under covered duopoly, the environmental damage is:

$$
D_{C}=D_{C}^{L}+D_{C}^{H}=\frac{1}{b}\left[\frac{q_{L}}{2}(b+\gamma)+\frac{q_{H}}{2}(b-\gamma)\right] .
$$

Both components of damage $\left(D_{C}^{L}\right.$ and $\left.D_{C}^{H}\right)$ decrease linearly with the environmental qualities $q_{H}$ and $q_{L}$. Interestingly, the stealing effect does not play any role because the market share of each firm is independent of the rival's environmental quality. Therefore, $D_{C}^{i}$, the damage coming from producer $i$, increases with $q_{i}$, while being independent of $q_{j}$, with $i, j=H, L$ and $i \neq j$. We thus conclude that, in this equilibrium market configuration, imposing a MQS would unambiguously reduce total damage.

Finally, consider the case in which the market is monopolized by the green firm. In the uncovered monopoly, the environmental damage writes as

$$
D_{M}=q_{L} \frac{b q_{L}-c+\gamma\left(q_{H}-q_{L}\right)}{2 q_{L}}=\frac{b q_{L}-c+\gamma\left(q_{H}-q_{L}\right)}{2 b} .
$$

Improving the environmental quality of the brown good unambiguously reduces the environmental damage. At first sight, this finding can be counterintuitive, given that the brown firm is inactive.

\footnotetext{
${ }^{40}$ We include in the Appendix (see Proof of Proposition 3) the precise expressions of the threshold values of $\gamma$ that are mentioned in this section.
} 
However, it may undertake an abatement effort with the aim of re-entering the market. Notice that the market share of the green firm is affected by the quality produced by the brown producer; the more pollutant the brown good, the larger the market share of the green firm, and thus the higher the corresponding damage. In this circumstance, the abatement effort undertaken by the brown firm indirectly reduces the damage. The same finding does not hold in the covered monopoly, in which the damage coincides with the per-unit emissions of the green good, $q_{L}$. The brown firm no longer plays a role in determining the damage since the market share of the green producer is no longer affected by the environmental quality of the potential rival. ${ }^{41}$

We can now summarize our results:

Proposition 3 Improving the environmental quality of the brown firm reduces the total damage: (i) unambiguously in case of covered duopoly and uncovered green monopoly; (ii) whenever the reduction in damage due to the technique effect is stronger than the corresponding increase brought on by the stealing effect, in case of uncovered duopoly.

Proof. See the Appendix.

It is worth noting that, in contrast with the environmental damage, the duopoly profits differently react to a reduction in $q_{H}$. Under uncovered duopoly the profits of the brown firm increase when $q_{H}$ diminishes for $\gamma$ sufficiently high and vice versa. However, when $\gamma$ is large enough to induce market coverage, its profits decrease when $q_{H}$ reduces. Therefore, for a given $q_{L}$, the brown firm benefits from abating per-unit emissions as long as the social component of consumption is large and the market is uncovered. On the contrary, for relatively low values of $\gamma$, the brown firm would be tempted to increase its hedonic quality $q_{H}$ in absence of the policy instrument. Thus, imposing a MQS becomes more relevant as $\gamma$ decreases.

In the case of uncovered green monopoly, improving the environmental quality of the brown good reduces the profits of the green firm. This is not surprising. The brown producer affects the equilibrium profits of the rival even in the case when it is not active in the market via the price competition driver and the social component driver. The trade-off between hedonic and social component of quality is such that, when the brown producer increases the hedonic quality of its variant, it reduces the quality gap. Reducing this gap immediately decreases the equilibrium profits of firm $L$ as it typically observed in a vertically differentiated market. This effect is then magnified or weakened by the social component of consumption. ${ }^{42}$

Interestingly, one can conclude that the incentive for firms to support or rather oppose a MQS change with the market structure. For example, there exists circumstances where a MQS is supported by the brown producer but opposed by the green firm. This happens in case of green monopoly where

\footnotetext{
${ }^{41}$ In a way, this result is reminiscent of the natural monopoly property while the one observed in the case of uncovered monopoly resembles the potential competition in the contestable markets.

${ }^{42}$ Notice that this finding can be extended to the case of covered green monopoly.
} 
the effort to curb emissions undertaken by the brown firm reduces the equilibrium profit of the green firm. This may possibly enable the brown competitor to re-enter the market. Under uncovered duopoly, the brown firm supports the introduction of a MQS whenever the social component of consumption is sufficiently strong, otherwise its equilibrium profits decrease when it improves the environmental quality of its variant at the expense of the hedonic dimension. Still, at this market configuration, the green firm does not benefit from an increase of the environmental quality of the brown variant. Since its equilibrium profits decrease with the greenness of the competing good, it firm opposes the introduction of a MQS. Finally, both firms are unambiguously damaged by the introduction of a MQS under covered duopoly, since their equilibrium profits decrease with the environmental quality of the brown variant. In this circumstance, no firm finds it profitable to support this policy measure. Table 2 summarizes these results.

Table 2: Impact of a MQS (reduction of $q_{H}$ for given $q_{L}$ )

\begin{tabular}{|l|l|l|}
\hline & Environmental damage & Profits \\
\hline UD & $D_{D}$ either $\downarrow$ or $\uparrow$ & $\pi_{L}^{*} \downarrow$ \\
& $\pi_{H}^{*}$ either $\downarrow$ or $\uparrow$ \\
\hline CD & $D_{C} \downarrow$ & $\pi_{L}^{C} \downarrow$ \\
& $\pi_{H}^{C} \downarrow$ \\
\hline UGM & $D_{M} \downarrow$ & $\pi_{L}^{M} \downarrow$ \\
\hline
\end{tabular}

$\mathrm{UD}=$ Uncovered duopoly, $\mathrm{CD}=$ Covered duopoly, $\mathrm{UGM}=$ Uncovered green monopoly

Finally, although it is reasonable to assume that by definition the green firm satisfies the MQS on emissions, it may well happen that the MQS imposed by the policy maker is binding for both firms. Looking at (16), it is relatively easy to assess the effect on total damage from a joint abatement effort in case of covered duopoly. Indeed, in this scenario, as there is no stealing effect, improving the environmental qualities would clearly reduce the damage. As for the cases of uncovered duopoly and monopoly, we can capture the net effect of a joint abatement effort through a complementary assessment of a unilateral investment of the green firm. To this aim, we consider how $D$ changes with $q_{L}$ for a given $q_{H}$. Under uncovered duopoly, similarly to the above analysis, increasing the environmental quality of the green firm has two effects: a direct technique effect that calls for a reduction of total damage, and an indirect effect due to the fact that reducing $q_{L}$ amplifies the hedonic quality gap thereby softening the price competition in the market. In this case, the market share of the brown firm decreases thereby reducing the corresponding damage, whereas the market share of the green firm can decrease. Namely, the green firm expands its market if $\gamma$ is very significant. Nevertheless, from algebraic computations, we find that the net effect on total damage is clear-cut: it always decreases. Indeed, the reduction in damage deriving from the brown firm outweighs the increase in the damage coming from the green producer. We can conclude that, if both firms invest in abatement, the net effect on total damage depends on the intensity of their effort. If the green 
producer invests more (resp. less) than the rival, the environmental quality gap increases (resp. decreases). In this circumstance, the mechanism arising when only the green (resp. brown) firm invests in abatement applies. Finally, under uncovered monopoly, we find that an abatement effort by the green firm increases total damage as its market share enlarges and this output expansion effect prevails over the technique effect. If both firms pursue the investment, the net effect on total damage depends on the intensity of the effort of each player, as described in the case on uncovered duopoly.

\section{A discussion of our main assumptions}

Our model has been developed under two key assumptions. First, we assume the existence of relative preferences for environmental quality. Still, in several circumstances consumers also care about the absolute level of emissions coming from a product rather then focusing on the absolute environmental quality of a product. Moreover, our relative preferences are linked to two vertical attributes (hedonic vs environmental quality), whereas one may argue that consumers often develop brand loyalty, so that a true horizontal attribute could play a role.

The second key assumption regards production costs. We assume that production costs are nil for the production of the brown good but positive and variable in quantity for the green good. Therefore, in a very stylized way, the production costs depend on the environmental quality. However, different cost structures may be considered depending on the type of abatement effort enacted by firms.

We next discuss with some formal details how our assumptions could be relaxed based on the above considerations.

\subsection{Relative and absolute preferences for environmental quality}

Consumers may care about absolute levels of emissions for several reasons. For instance, they may benefit from different forms of rewards when buying environmentally friendly goods. In the automotive sectors, under the European Green Cars Initiative funded by the European Commission, the reduction of car registration taxes on low $\mathrm{CO} 2$ cars aimed to stimulate green car purchases through monetary benefit. ${ }^{43}$ Accordingly, the omission of absolute preferences for environmental quality is questionable and one may wonder how the main findings of our model would change when introducing this further ingredient in the analysis.

A natural entry point for nesting absolute preferences in our framework is to write the indirect utility function of consumer type $\theta$ as follows:

$$
U(\theta)=\left\{\begin{array}{c}
\theta q_{H}-p_{H}-\gamma\left(q_{H}-q_{L}\right)-\mu e_{H}, \text { if she buys the high quality but brown good, } \\
\theta q_{L}-p_{L}+\gamma\left(q_{H}-q_{L}\right)-\mu e_{L}, \text { if she buys the low quality but green good, } \\
0, \text { if she refrains from buying. }
\end{array}\right.
$$

\footnotetext{
${ }^{43}$ Along the same rationale, when purchasing electric vehicles, drivers are provided by local governments with preferential parking permits in urban areas (e.g., City of Amsterdam) or authorization to drive in bus and taxi lanes.
} 
The parameter $\mu \in(0, b)$ describes the consumers' sensitivity to the absolute level of emissions coming from the goods they purchase. Recalling that $e_{i}=\phi q_{i}$ and $\phi=1$, the utility from buying good $i$ can be written as $q_{i}(\theta-\mu)-\gamma\left(q_{i}-q_{j}\right)-p_{i}$ with $i, j=\{L, G\}$ and $j \neq i$. Note that this new formulation can also capture, with minor changes, the idea that consumers are only concerned with the absolute level of emissions. For this to be evident, it suffices to drop from the above utility function the relative preferences. ${ }^{44}$

It is easy to see that the introduction of the parameter $\mu$ induces a reduction of consumers' willingness to pay for the good $i$, for any consumer type $\theta$. In particular, the consumer that is indifferent between buying the low quality good and not buying at all now writes:

$$
\theta_{L}^{\prime}=\mu+\frac{p_{L}-\gamma\left(q_{H}-q_{L}\right)}{q_{L}}
$$

with $\theta_{L}^{\prime}>0 \Longleftrightarrow p_{L}>\gamma\left(q_{H}-q_{L}\right)-\mu q_{L}$; the consumer that is indifferent between buying the low quality good and the high quality good becomes:

$$
\theta_{H}^{\prime}=\mu+2 \gamma+\frac{p_{H}-p_{L}}{q_{H}-q_{L}} .
$$

Ceteris paribus, $\theta_{i}^{\prime}-\theta_{i}=\mu>0$ for $i=H, L$. Thus, for any price pair $\left(p_{H}, p_{L}\right)$, it emerges a rightward shift equal to $\mu$ of the indifferent types of consumers with respect to the baseline model. ${ }^{45}$ Although this shift does not change our qualitative findings, it determines several interesting implications. First, from the equilibrium analysis carried out in the baseline model, we know that the brown firm is indifferent between producing and not producing when $\theta_{H}^{*}=b$ at $\gamma=\bar{\gamma}$ (see proof of Lemma 2 in Appendix). Given that now $\theta_{H}^{*^{\prime}}=\theta_{H}^{*}+\mu$, it immediately follows that, at $\gamma=\bar{\gamma}$, the brown firm is no longer active in the market since $\theta_{H}^{*^{\prime}}(\bar{\gamma})>b$. Therefore, in this new setting, the brown producer is indifferent between producing or not at $\gamma=\bar{\gamma}^{\prime}<\bar{\gamma}$, namely the market can be monopolized by the green firm for a lower value of $\gamma$. Along the same rationale, we can observe that, differently from the baseline model where $\theta_{L}^{*}(\hat{\gamma})=0$, under absolute preferences the market is uncovered at $\gamma=\hat{\gamma}$ since $\theta_{L}^{*^{\prime}}(\hat{\gamma})>0$ while it is covered at some $\hat{\gamma}^{\prime}>\hat{\gamma}$. Finally, it is immediate to

\footnotetext{
${ }^{44}$ Formally, the utility of a consumer $\theta$ when purchasing the variant $i$ writes as $U(\theta)=(\theta-\mu) q_{i}-p_{i}$, with $i=H, L$. Then, the analysis can be immediately reconciled with a traditional approach of vertical differentiation where the willingness to pay of a consumer $\chi$, with $\chi=\theta-\mu$ depends both on the willingness to pay for the hedonic quality $\theta$ and the one for the environmental quality $\mu$. The main findings of this model can be easily derived from an uncovered duopoly market with vertical product differentiation.

${ }^{45}$ It is worth noting that the utility function (18) resembles the one adopted in the literature on two-dimensional vertical differentiation (see in particular Vandenbosch and Weinberg, 1995): when removing the relative preferences, the utility in our model depends on the absolute vertical attributes of the good. However, we do not share the main scope of these models centering around the effects of the "demand force" and "strategic force" on the "positioning of firms" and optimal differentiation between pair of attributes (see Lauga and Ofek, 2011).
} 
see that the demand functions faced by firms $H$ and $L$ translate respectively as follows:

$$
\begin{aligned}
& x_{H}^{\prime}=\frac{1}{b}\left(b-\theta_{H}^{\prime}\right)=\frac{1}{b}\left[b-\left(\mu+2 \gamma+\frac{p_{H}-p_{L}}{q_{H}-q_{L}}\right)\right] \\
& x_{L}^{\prime}=\frac{1}{b}\left(\theta_{H}^{\prime}-\max \left\{\theta_{L}^{\prime}, 0\right\}\right)=\left\{\begin{array}{c}
\frac{1}{b}\left[\frac{p_{H} q_{L}-q_{H} p_{L}}{q_{L}\left(q_{H}-q_{L}\right)}+\frac{\gamma\left(q_{H}+q_{L}\right)}{q_{L}}\right] \text { if } \gamma<\frac{p_{L}+\mu q_{L}}{\left(q_{H}-q_{L}\right)}, \\
\frac{1}{b}\left(\mu+2 \gamma+\frac{p_{H}-p_{L}}{q_{H}-q_{L}}\right) \text { if } \gamma \geq \frac{p_{L}+\mu q_{L}}{\left(q_{H}-q_{L}\right)} .
\end{array}\right.
\end{aligned}
$$

Interestingly, plugging the equilibrium prices in the above functions, we observe that, with respect to the baseline model, in case of uncovered market, the market share of both goods decreases, whereas in the corner coverage equilibrium the market share of the brown firm decreases as much as the market share of the green firm increases. ${ }^{46}$ Therefore, we can unambiguously state that the absolute concern always reduces the environmental damage at equilibrium. In the case of uncovered market, not only does the output of the brown firm decrease but also total output; in case of covered market (that is, for a given total output) there is a redistribution of market shares from the more polluting to the less polluting firm. In our paper, we can explain the above findings as follows. On one hand, the disutility borne by consumers when they care about the absolute level of emissions reduces by $\mu$ their willingness to pay for a good, whatever its hedonic quality. On the other hand, the absolute concern $\mu e_{i}$ affects firms in an asymmetric way, since $e_{H}>e_{L}$. As a result, the brown firm is afflicted more than its green rival.

The above analysis proves that:

Proposition 4 When consumers display both relative and absolute preferences for environmental quality, for any given b, compared with the baseline model: (i) the green firm monopolizes the market at lower levels of $\gamma$, (ii) the market coverage by the green firm occurs at higher levels of $\gamma$, (iii) the environmental damage always decreases.

\subsection{Incorporating Horizontal Differentiation}

In several cases, beyond considering the quality of goods, either hedonic or environmental, consumers make decisions based on the brands they trust. As a consequence, ceteris paribus, they prefer to purchase brands that are closer to their preference in the product space. Considering again the automotive sector, quite often consumers base their purchasing decisions on their loyalty to a specific brand. This can also be due to some monetary benefits which companies offer in the case of repeated purchases. ${ }^{47}$ Then, one may think of fuel efficiency as the environmental vertical attribute, pure performance as the hedonic vertical attribute, and brand as the horizontal attribute. We analyze how the baseline model reacts to the introduction of a horizontal attribute in the utility function.

\footnotetext{
${ }^{46}$ For further details, see in the Appendix the section entitled Absolute preferences.

${ }^{47}$ Typically, BMW guarantees to its customers considerable discounts in case of repeated purchases.
} 
Assume that a share $\lambda \in(0,1)$ of consumers prefers the brand produced by the brown firm $H$, while the remaining share $(1-\lambda)$ prefers that produced by the green firm $L$. When buying their preferred brand, consumers enjoy an extra benefit captured by parameter $\alpha>0$, which is independent from the relative environmental performance of the two products. Thus, the utility of $i$-loyal consumers is given by

$$
U^{i}(\theta)=\left\{\begin{array}{c}
\theta q_{i}-p_{i}-\gamma\left(e_{i}-e_{j}\right)+\alpha, \text { if she buys the quality variant } i \\
\theta q_{j}-p_{j}+\gamma\left(e_{i}-e_{j}\right), \text { if she buys the quality variant } j \\
0, \text { if she refrains from buying. }
\end{array}\right.
$$

Additional superscript $i=H, L$ denotes consumers that prefer brand $i$ over $j=L, H$, with $j \neq i$. We need to assume that $\alpha$ is not too strong, otherwise horizontal differentiation would outweigh vertical differentiation and consumers would simply base their decision depending on the brand characteristic that they prefer. In this extended version of our model the demand for each good is derived as the sum of its demand coming from the share $\lambda$ of $H$-loyal consumers and its demand coming from the share $(1-\lambda)$ of $L$-loyal consumers. ${ }^{48}$

Interestingly, this ingredient modifies the $\gamma$-intervals where the defining property of horizontal/vertical differentiation holds along two dimensions. First, it can be proven that, whatever $\lambda$, the parametric region where both firms have a positive demand at $p_{H}=p_{L}$ enlarges. Second, depending on $\lambda$, this enlargement can be coupled to either an expansion or a contraction of the parametric intervals where the hedonic and the environmental vertical differentiation hold.

The former implication is quite intuitive as one could expect that introducing a true horizontal attribute (in the form of brand loyalty) enlarges the parametric region where horizontal differentiation prevails. In contrast, the latter implication is much less obvious and it deserves a closer analysis. In particular, as long as $\lambda$ is not very high, namely $\lambda \leq 1 / 2$, the interval characterized by environmental vertical differentiation increases, while that with hedonic vertical differentiation reduces. However, for any $\lambda>1 / 2$, the reverse is not true. Indeed, the interval with environmental vertical differentiation decreases, while that with hedonic vertical differentiation does not enlarge. Thus, the benefit for firm $i$ deriving from the brand loyalty attitude $\alpha$ among the $i$-loyal consumers does not imply a corresponding penalty for firm $j$. This can be explained by analyzing the demand functions. Consider first the demand coming from the share of $H$-loyal consumers. Compared to the baseline model, the consumer that is indifferent between buying the low quality good and the high quality good, here labelled $\theta_{H}^{H}$, is such that $\theta_{H}^{H}<\theta_{H}$. On the contrary, the consumer that is indifferent between buying the low quality good and not buying at all does not change, namely $\theta_{L}^{H}=\theta_{L}$. It immediately follows that, given $p_{H}$ and $p_{L}$, the market share of $H$ increases at expenses of firm $L$

\footnotetext{
${ }^{48}$ This modelling strategy is inspired by Espìnola-Arredondo and Zhao (2012). They extend the Hotelling duopoly model by taking into account green consumerism distinguishing between green consumers and neutral consumers. With the due important formal differences, we follow their reasoning to solve the model. In particular, in the Appendix, we detail the assumption on $\alpha$ and we provide the modified total demand functions (see the section entitled Horizontal differentiation). The complete solution of this extended model is available upon request.
} 
by $\Delta_{H}=\lambda\left(\theta_{H}-\theta_{H}^{H}\right)=\lambda\left(\frac{\alpha}{q_{H}-q_{L}}\right)$. In contrast, when considering $L$-loyal consumers, we observe that $\theta_{H}^{L}>\theta_{H}$. Accordingly, for any price pair $\left(p_{H}, p_{L}\right)$, the market share of firm $H$ among $(1-\lambda)$ consumers decreases by $\Delta_{L}=(1-\lambda)\left(\theta_{H}^{L}-\theta_{H}\right)=(1-\lambda)\left(\frac{\alpha}{q_{H}-q_{L}}\right)$, while that of firm $L$ expands by the same amount. Hence, based only on the stealing effect, the presence of $\alpha$ benefits firm $H$ at the expense of the rival for any $\lambda>1 / 2$, and vice versa for $\lambda \leq 1 / 2$. Notice, however, that $\theta_{L}^{L}<\theta_{L}^{H}=\theta_{L}$, where $\theta_{L}^{L}$ indicates the consumer that is indifferent between buying the low quality good and not buying at all among $L$ - loyal buyers. Thus, when the market is uncovered, firm $L$ receives an additional benefit in terms of demand expansion, captured by $\Delta_{L}^{\prime}=(1-\lambda)\left(\theta_{L}-\theta_{L}^{L}\right)=(1-\lambda)\left(\frac{\alpha}{q_{L}}\right) \cdot{ }^{49}$ Therefore, the total demand expansion for firm $L$ is $\Delta_{L}^{T O T}=\Delta_{L}+\Delta_{L}^{\prime}=(1-\lambda) \frac{\alpha q_{H}}{\left(q_{H}-q_{L}\right) q_{L}}$ with $\Delta_{L}^{T O T}>\Delta_{H} \Leftrightarrow \lambda<\frac{q_{H}}{q_{H}+q_{L}} \equiv \lambda_{1} \in(1 / 2,1)$.

The effect of the introduction of a pure horizontal attribute on the parametric region where vertical differentiation prevails is therefore asymmetric. Whenever the proportion of green-loyal consumers is higher than that of brown-loyal consumers $(\lambda \in(0,1 / 2))$, the parametric interval where vertical hedonic differentiation occurs shrinks, while that of vertical environmental differentiation enlarges. At the other extreme, when the share of brown-loyal consumers is much higher than that of green-loyal consumers (namely, $\lambda \in\left[\lambda_{1}, 1\right)$ ), we observe vertical hedonic differentiation in a wider parametric interval, at the expense of vertical environmental differentiation. Otherwise, namely for $\lambda \in\left[1 / 2, \lambda_{1}\right)$, both intervals of vertical differentiation shrink. ${ }^{50}$

\subsection{Variable versus fixed costs}

The literature on abatement effort usually distinguishes between two types of environmental innovation: cleaner technologies and end-of-pipe technologies. "Cleaner production reduces resource use and/or pollution at the source by using cleaner production methods, whereas end-of-pipe technologies curb pollution emissions by implementing add-on measures." (Frondel et al., 2007, p. 572)..$^{51}$ Typically, with cleaner technologies the cost is assumed to be variable, whereas with end-of-pipe technologies it is assumed to be fixed (see, among others, Clemenz, 2010). Indeed, a cleaner technology entails a change in the production process so that per-unit of output emissions are lower but marginal production costs are higher, the cleaner the technology is. In the case of end-of-pipe technologies, some fraction of the pollutant is reduced without changing the production process. ${ }^{52}$

\footnotetext{
${ }^{49}$ In the case of market coverage, $\Delta_{L}^{\prime}$ is nil and the stealing effect turns out to be the main driver of the market configuration, given $p_{H}$ and $p_{L}$.

${ }^{50}$ Additional information are provided in the Appendix, again in the section Horizontal differentiation.

${ }^{51}$ Typical examples of end-of-pipe technologies are catalytic convertors on automobile tailpipes that reduce pollutant emissions after they have formed, whereas examples of cleaner production technologies are the use of environmentally friendly materials (e.g. replacing organic solvents by water) and modification of the combustion chamber design (process-integrated systems).

52 "Incineration plants (waste disposal), waste water treatment plants (water protection), sound absorbers (noise abatement), and exhaust-gas cleaning equipment (air quality control) are typical examples of end-of-pipe technologies. In contrast, cleaner production technologies are seen as directly reducing environmentally harmful impacts during the production process. The recirculation of materials, the use of environmentally friendly materials (e.g. replacing organic
} 
In spite of its simplicity, our assumption on costs enables us to capture the investment in cleaner investment since the variable cost is borne only by the green firm. Interestingly, this cost structure is consistent with the evidence that a market-based mechanism, such as a growing environmental consciousness among consumers, is more likely to induce cleaner technology investment, since application of end-of-pipe measures depends at least partially on regulatory pressure. ${ }^{53}$ Of course, given that end-of-pipe measures are largely widespread, considering whether our findings still hold when variable costs are replaced by fixed cost seems to be natural.

First, in line with a cleaner technology innovation, we extend the model to a more sophisticated environmental quality-specific cost structure. In particular, we assume that production costs increase with the environmental quality, namely $c_{i}\left(q_{i}\right)$, with $c^{\prime}\left(q_{i}\right)<0$ and $1 / q_{i}$ representing the environmental quality of the variant $i$. This is a reasonable assumption given that, for instance, increasing fuel efficiency may involve more adjustments on the functionality of the vehicle. Although this assumption would not modify the qualitative results of our equilibrium analysis, it would imply quantitative changes. In order to provide the intuition behind such a modification, one could assume that $c_{i}=c / q_{i}$. This describes a marginal cost of production that increases with the environmental quality (which in our model decreases with the hedonic quality). Introducing this cost structure implies that now also the brown firm bears a positive production cost, although it is lower than that of the green producer. ${ }^{54}$ A priori, with respect to the baseline model, this cost modification may favor either firm in terms of the equilibrium results. The per unit cost difference between the two firms is now given by $\frac{c}{q_{L}}-\frac{c}{q_{H}}=\frac{c\left(q_{H}-q_{L}\right)}{q_{H} q_{L}}$. By comparing the above expression with the cost difference in the baseline model, given by $c$, we find that $\frac{c\left(q_{H}-q_{L}\right)}{q_{H} q_{L}}>c \Longleftrightarrow q_{L}<\frac{q_{H}}{\left(q_{H}+1\right)}$. Assuming without loss of generality that $q_{H}=1$, we can observe that if the quality gap is high enough $\left(q_{L} \in(0,1 / 2)\right)$, then the cost difference increases, thereby rendering the green firm worse off in comparison with the baseline model. ${ }^{55}$ This is quite intuitive because the cost disadvantage for the less polluting firm is relatively large. Therefore, on the one hand, this reduces the parametric regions where both a green monopoly prevails and/or where the market is covered. On the other hand, it increases those where a duopoly occurs, and where the brown firm monopolizes the market. As for the price switch, it appears now in a larger parametric region, as the price charged by the green firm augments in response to the higher cost difference. On the contrary, if the quality gap is low $\left(q_{L} \in[1 / 2,1)\right)$, the green firm is

solvents by water), and the modification of the combustion chamber design (process-integrated systems) are examples of cleaner production technologies (Frondel, p. 573)". Although cleaner production technologies are better "for both environmental and economic reasons", they are often hampered by costly and time-consuming investment needed to their development and implementation.

${ }^{53}$ See Frondel et al. (2007) among others.

${ }^{54}$ We could have considered a positive cost only for the green firm, increasing in quality, such as $c / q_{L}$. The qualitative results would have not changed, as one can easily demonstrate. Additional calculations are available upon request.

${ }^{55}$ The formal analysis remains unchanged, and the results of Proposition 2 can be easily replicated. However, in terms of the equilibrium representations which appear in Figure 1, a higher cost difference has the same qualitative effect as a higher marginal cost $c$. As it enters into the firms' maximization process, an increases in $c$ causes an upward shift in all the relevant threshold values of $\gamma$ except $\widetilde{\gamma}$, which moves downward. 
better off because its cost disadvantage reduces. Mutatis mutandis, both the monopolization of the green firm and the market coverage occur for comparatively lower level of $\gamma$, while the price switch requires a higher level of the social component. Obviously, the parametric region where the brown firm monopolizes the market tends to shrink.

Secondly, we can introduce a fixed cost for the green firm enacting end-of-pipe abatement effort. More precisely, we can assume that, while the profit function of the brown firm remains the same, that of the green firm now writes $\pi_{L}=p_{L} \cdot x_{L}-F$, so that both firms have variable production costs equal to zero. It can be shown that the qualitative results of the baseline model (Proposition 2) are robust to this cost modification, including the comparative statics of equilibrium variables with respect to $b$ and $\gamma^{56}$ The main difference with the baseline model is represented by the fact that the fixed cost $F$ does not enter the firms' maximization process. This has two relevant consequences. First, most of the relevant $\gamma$-threshold values shift downward, given that per unit cost difference is now equal to zero. Ceteris paribus, this enlarges the parametric regions where market coverage and green monopolization occur, as we know from the discussion above, provided the green firm is active. Indeed, the only condition that depends on $F$ is related to the presence of the green firm in the market; when $F$ is relatively high, the market is monopolized by the brown producer. Second, consider what happens both in the baseline model and in the modified model when the respective costs increase. As we already explained, when marginal cost $c$ increases, the whole equilibrium configuration is affected and both market coverage and green monopolization occur in a smaller parametric region. On the contrary, for higher levels of $F$, although it still remains true that the green producer finds it harder to survive, its chances to dominate the market, and even to cover it, are left unchanged.

\section{Conclusions}

In this paper, we have considered a situation in which a "clean" and a "dirty" firm compete in the market by offering two products. They are differentiated along two dimensions, hedonic quality and environmental quality, and characterized by a trade-off between these two vertical attributes. An environmentally friendly good satisfies the consumer desire to stand out as a good citizen, while leaving her unsatisfied due to poor performance.

Our findings can be summarized as follows. First of all, our model departs from a traditional vertical differentiation setting, belonging rather to a hybrid category where in some circumstances the defining property of vertical differentiation ceases to hold and consumers no longer uniformly prefer a good over the alternative one. As a result, we find parametric regions where a price switch emerges, with the low hedonic quality variant being sold at a higher price than the high hedonic quality one. This occurs as a result of a quality switch, so that, at equal prices, all consumers prefer the green good. In this case, the price switch is based on a vertical differentiation mechanism, given that the

\footnotetext{
${ }^{56}$ The complete solution of the model with the fixed cost of greenness is available upon request.
} 
green variant is considered also of high quality due to the dominance of the social component. The price switch may also appear in a setting in which only some consumers prefer the green good to the brown alternative, if they are sold at the same price. In such a case, however, the switch can no longer be attributed to a vertical differentiation mechanism. Rather, the defining property of competition is here associated to horizontal differentiation.

Secondly, when the social component of consumption is strong enough, then the market can be monopolized by the green producer. It is worth noting that this result cannot be observed in a vertically differentiated market where the lower bound of the market is nil. Typically, in this situation there is always room in the market for two firms, as a natural monopoly setting requires the market to be covered. Thirdly, differently again from the traditional vertical differentiation, where market coverage never occurs when the lowest willingness to pay is nil, the green firm can find it profitable to cover the market in the case of monopoly.

It is worth remarking that, if these two dimensions of product differentiation were not in contrast with each other, then the equilibrium analysis would change. If the green product were also of high hedonic quality, then we would never observe the price switch nor the market coverage scenario, since the initial disadvantaged position due to the low (hedonic) quality would be amplified by the social stigma associated to the production of the brown good. Interestingly, our model can be reconciled with this setting where the trade-off is absent: for this to be evident, it suffices to focus on the range of parameters such that one dimension of quality, either the hedonic or the environmental one, unambiguously prevails over the other. As an example, consider the case in which the environmental quality dominates the hedonic quality. Then, our approach can be intended as a vertically differentiated model with the environmental quality being the driver of consumption. Consistently with the framework without trade-off, we observe that at equilibrium either the market is served by two producers with the price of the green variant being higher than the brown one, or only the green firm is active.

Finally, we develop some policy considerations. In particular, we wonder whether the traditional effects of a MQS described in a vertically differentiated duopoly still hold when consumption is also driven by a social component. We consider the cases in which a MQS affects only the brown producer or both producers and investigate the impact on total damage of this regulation in comparison with standard duopoly models. From the above considerations, it derives that the social dimension of consumption provides an incentive to specialize in green production. Indeed, the green firm can benefit from a price premium or even monopolize the market for sufficiently high values of such a component. An immediate consequence of this statement is that, contrary to what is somehow argued, consumers may have a proactive role in reducing pollution. Nesting the conflict between the social component of consumption and the individual rationality-based motive in the traditional utility function enables us to show how this role can be carried out. Interestingly, we have shown 
that imposing a MQS may have ambiguous effects on the total environmental damage. Indeed, an abatement effort carried out by the brown firm may result in an increase of the environmental damage whenever the social component of consumption is very strong. This is due to the stealing effect that prevails upon the technique effect, and it becomes even more evident when consumers also care about the absolute level of environmental quality. In such a case, although the environmental damage is less pronounced than in the baseline model, the negative effect of imposing a MQS may emerge for lower levels of relative preferences. This consideration opens the door to further research questions. For instance, one may investigate the optimal mix of environmental policy under the assumption of relative and absolute preferences for environmental quality.

\section{Appendix}

\section{Proof of Lemma 1}

First, observe that the interval $[\max \{0, \underline{\gamma}\}, \max \{\bar{\gamma}, b\})$ is non-empty for $b>\underline{b}$ given that $\underline{\gamma}>$ $0 \Longleftrightarrow b<b_{0}$ with $b_{0}>\underline{b}, \bar{\gamma}>\underline{\gamma} \Longleftrightarrow b>\underline{b}$ and $\bar{\gamma}>b \Longleftrightarrow b<\widehat{b}$. Notice also that the interval $[\widehat{\gamma}, b)$ is non-empty only for $b>\widehat{\widehat{b}}$, given that $\widehat{\gamma}<b \Longleftrightarrow b>\widehat{b}$. Secondly, following the previous discussion, equilibrium candidates (6) and (7) verify that $p_{L}^{*}>c, p_{H}^{*}>0$ and $0<\theta_{L}^{*}<\theta_{H}^{*}<b$ only when $\gamma \in[\max \{0, \underline{\gamma}\}, \min \{\bar{\gamma}, \hat{\gamma}\})$, where:

$$
\begin{aligned}
\theta_{L}^{*} & =\frac{2 c q_{H}-\left(q_{H}-q_{L}\right)\left[2 \gamma q_{H}-(b+\gamma) q_{L}\right]}{\left(4 q_{H}-q_{L}\right) q_{L}}, \\
\theta_{H}^{*} & =\frac{\left(q_{H}-q_{L}\right)\left[(2 b+3 \gamma) q_{H}-(b+\gamma) q_{L}\right]-c q_{H}}{\left(4 q_{H}-q_{L}\right)\left(q_{H}-q_{L}\right)} .
\end{aligned}
$$

Indeed, for $\gamma \geq \widehat{\gamma}$ (which is possible only when $b \geq \widehat{b}$ ) $\theta_{L}^{*} \leq 0$ and the market is covered. However, an interior duopoly solution with covered market cannot be sustained at equilibrium, as it can be easily verified. In such a case, therefore, a duopoly with the market covered at the limit becomes the equilibrium candidate. This equilibrium configuration is characterized by constrained price competition. As the market is covered at the limit, the indifferent consumer $\theta_{L}$ defined in (1) is set equal to zero, and demand functions are $x_{L}=\theta_{H} / b$ and $x_{H}=\left(b-\theta_{H}\right) / b$. Accordingly, the equilibrium price of the green good is given by $p_{L}^{C}>c$ (see 12). Inserting $p_{L}^{C}$ into the best reply of the high quality firm and solving, we obtain (13), and $p_{H}^{C}$ is strictly positive iff $\gamma<b$. Hence, when $\gamma \geq \hat{\gamma}$, there is still room for both producers and the market is covered at the limit only when $\gamma<b$.

\section{Proof of Remark 1}

At the interior duopoly equilibrium, we find that:

$$
p_{L}^{*} \gtreqless p_{H}^{*} \Longleftrightarrow \gamma \gtreqless \frac{b\left(2 q_{H}^{2}-3 q_{H} q_{L}+q_{L}^{2}\right)-c q_{H}}{\left(q_{H}-q_{L}\right)\left(5 q_{H}-q_{L}\right)} \equiv \widetilde{\gamma}
$$


Moreover, it is straightforward to verify that $\widetilde{\gamma} \in(0, \min \{\bar{\gamma}, \widehat{\gamma}\})$ when $q_{H} / q_{L} \in(1,2)$. In such a case, then, the price set by the green producer is higher than that set by the brown one when $\gamma \in(\widetilde{\gamma}$, $\min \{\bar{\gamma}, \widehat{\gamma}\})$. The opposite holds in $\gamma \in(0, \widetilde{\gamma}]$. Consider the covered duopoly at the limit, which holds when $\gamma>\widehat{\gamma}$ and $b>\widehat{b}$. We obtain that:

$$
p_{H}^{C}>p_{L}^{C} \Longleftrightarrow \gamma<\frac{b}{3}
$$

However, it is immediate to verify that:

$$
\widehat{\gamma}-\frac{b}{3}=\frac{2\left[3 c q_{H}-b\left(q_{H}-q_{L}\right)\left(q_{H}-2 q_{L}\right)\right]}{3\left(q_{H}-q_{L}\right)\left(2 q_{H}-q_{L}\right)}>0
$$

given that we are limiting our attention to the case where $q_{H} / q_{L} \in(1,2)$. When the duopoly is covered at the limit, we then obtain that $p_{H}^{C}<p_{L}^{C}$.

\section{Proof of Remark 2}

First of all, we insert $p_{L}^{*}$ in $b_{D}\left(p_{L}\right)$ and impose $\gamma=\widetilde{\gamma}$ to and verify that:

$$
\gamma^{H}>\gamma^{L}\left(\left.p_{L}^{*}\right|_{\gamma=\widetilde{\gamma}}\right) \Longleftrightarrow b \geq \frac{4 c q_{H}}{\left(q_{H}+q_{L}\right)\left(3 q_{H}+q_{L}\right)} \equiv b_{D}^{*} .
$$

Moreover, in such a case,

$$
\left.x_{L}\right|_{p_{H}^{*}=p_{L}^{*}}>0 \Longleftrightarrow \gamma>\frac{2 c q_{H}+b\left(q_{H}-q_{L}\right) q_{L}}{2 q_{H}^{2}+5 q_{H} q_{L}-q_{L}^{2}} \equiv \gamma_{I D}^{L},
$$

where $I D$ stands for Internal Duopoly. It is immediate so show that $\underline{b}<b_{D}^{*}<b_{0}$ and that $\gamma^{H}>\gamma_{I D}^{L}$ when the duopoly is uncovered. When the market is covered at the limit, $\left.x_{L}\right|_{p_{H}^{*}=p_{L}^{*}}>0 \Longleftrightarrow \gamma>0$. Obviously, vertical hedonic differentiation cannot prevail when $\gamma \in[\widehat{\gamma}, b)$.

All in all, under the conditions sustaining a duopoly (both covered and uncovered), market competition between the green and the brown producer can be described by either horizontal or vertical differentiation. In particular, when $\gamma \in\left[\max \{0, \underline{\gamma}\}, \gamma_{I D}^{L}\right)$, the duopoly market is characterized by hedonic vertical differentiation, as the social component of consumption is very weak. For $\gamma \in$ $\left[\gamma_{I D}^{L}, \gamma^{H}\right)$ horizontal differentiation prevails as both firms would obtain a positive market share even when charging the same price. It is also possible to demonstrate that $\widetilde{\gamma} \in\left[\gamma_{I D}^{L}, \gamma^{H}\right)$, thus revealing that the price switch occurs when products are perceived as horizontally differentiated. Finally, in $\gamma \in\left[\gamma^{H}, \max \{\bar{\gamma}, b\}\right)$, the duopoly is characterized by environmental vertical differentiation, given that consumers attach a significantly value to the environmental dimension of quality.

\section{Proof of Lemma 2}

The proof aims at demonstrating that, when $\gamma>\max \left\{\underline{\gamma}^{M}, \bar{\gamma}, b\right\}$, two conditions are simultaneously verified: (i) the brown firm is not active in the market, neither at the duopoly nor at the 
monopoly equilibrium; (ii) the equilibrium price charged by the green firm when it holds a monopoly position is higher than its marginal cost. First, notice that:

$$
\max \left\{\underline{\gamma}^{M}, \bar{\gamma}, b\right\}=\left\{\begin{array}{c}
\underline{\gamma}^{M} \text { if } b \leq \underline{b}, \\
\bar{\gamma} \text { if } b \in(\underline{b}, \widehat{b}), \\
b \text { if } b \geq \widehat{b} .
\end{array}\right.
$$

Let us start from the brown firm. At the internal duopoly equilibrium, $p_{H}^{*} \geq 0 \Longleftrightarrow \gamma \leq \bar{\gamma}$, as we know from (9). When $\gamma>\bar{\gamma}$, then $p_{H}^{*}<0$ and the brown firm would stop producing. Consider now $\gamma \in(\bar{\gamma}, \underline{\gamma})$, which holds in $b \in[0, \underline{b}]$. Following (8), there exists the possibility for the brown producer to monopolize the market, given that $p_{L}^{*}<c$. In such a case, its profit would be $\pi_{H}^{M}=p_{H}\left\{b-\left[p_{H} / q_{H}+\gamma\left(q_{H}-q_{L}\right) / q_{H}\right]\right\}$. We compute the equilibrium price (15) and find that:

$$
p_{H}^{M}>0 \Longleftrightarrow \gamma<\frac{b q_{H}}{\left(q_{H}-q_{L}\right)} \equiv \bar{\gamma}^{M} .
$$

However, $\bar{\gamma}^{M}<\bar{\gamma}$ in $b \in[0, \underline{b}]$. This implies that $p_{H}^{M}<0$ in $\gamma>\bar{\gamma}$. The brown monopoly is therefore excluded from the market when $\gamma \in(\bar{\gamma}, \underline{\gamma})$. Finally, from the demonstration of Lemma 1, we know that, when the market is a duopoly covered at the limit, $p_{H}^{C} \geq 0$ when $\gamma \leq b$. Therefore, we need to impose $\gamma>b$ to remove the possibility for the brown producer to be active. To sum up, parametric restrictions ensuring that the brown firm is not active in the market boil down to $\gamma>\max \{\bar{\gamma}, b\}$.

As for the green producer, in absence of the brown rival, it would obtain monopoly profit $\pi_{L}^{M}=$ $\left(p_{L}-c\right)\left[b q_{L}-p_{L}+\gamma\left(q_{H}-q_{L}\right)\right] / q_{L}$. The resulting equilibrium price is (14), and

$$
p_{L}^{M} \geq c \Longleftrightarrow \gamma \geq \frac{c-b q_{L}}{q_{H}-q_{L}} \equiv \underline{\gamma}^{M}
$$

Therefore, we have to introduce the additional condition $\gamma \geq \underline{\gamma}^{M}$. As we notice above, $\max \left\{\underline{\gamma}^{M}, \bar{\gamma}, b\right\}=$ $\underline{\gamma}^{M}$ if $b \in[0, \underline{b}]$. We also have to verify that $0<\theta_{L}^{M}<b$. We can easily find that:

$$
\begin{aligned}
0 & <\theta_{L}^{M} \equiv \frac{c-\gamma q_{H}+(b+\gamma) q_{L}}{2 q_{L}} \Longleftrightarrow \gamma<\frac{c+b q_{L}}{q_{H}-q_{L}} \equiv \gamma_{M}, \\
\theta_{L}^{M} & \leq b \Longleftrightarrow \gamma \geq \frac{c-b q_{L}}{q_{H}-q_{L}} \equiv \underline{\gamma}^{M} .
\end{aligned}
$$

This verifies that the market is characterized at equilibrium by green monopolization when $\gamma>$ $\max \left\{\underline{\gamma}^{M}, \bar{\gamma}, b\right\}$. The market is uncovered if $\gamma<\gamma_{M}$, with $\gamma_{M} \geq \max \left\{\underline{\gamma}^{M}, \bar{\gamma}, b\right\}$, and covered when $\gamma \geq \gamma^{M}$. In the latter case, the equilibrium price is given by (12).

\section{Proof of Lemma 3}

Two conditions have to simultaneously hold when $\gamma<\min \left\{\underline{\gamma}, \bar{\gamma}^{M}\right\}$. First, the green firm can not be active in the market. As we know from (8), $p_{L}^{*}<c$ when $\gamma<\underline{\gamma}$. This requires $b \in\left[0, b_{0}\right)$, as we know from (10). Second, the price charged by the brown firm when it acts as a monopolist has to be positive. From the demonstration of Lemma 2, $p_{H}^{M}>0$ when $\gamma<\bar{\gamma}^{M}$. This always holds in 
$b \in\left(\underline{b}, b_{0}\right]$, where it is immediate to demonstrate that $\underline{\gamma}<\bar{\gamma}^{M}$. On the contrary, in $b \in[0, \underline{b}]$ we find that $\bar{\gamma}^{M}<\underline{\gamma}$, and therefore we have to impose the additional condition that $\gamma<\bar{\gamma}^{M}$ for $p_{H}^{M}>0$. To sum up, when $b \in\left[0, b_{0}\right)$, only the brown firm remains active in the market when $\gamma<\min \left\{\underline{\gamma}, \bar{\gamma}^{M}\right\}$.

\section{Proof of Lemma 4}

From (11), $\bar{\gamma}<\underline{\gamma}$ when $b \in[0, \underline{b}]$, thus complicating our analysis. Consider first $\gamma<\bar{\gamma}(<\underline{\gamma})$. Firm $L$ cannot be active at the internal duopoly, given that, from (8), $p_{L}^{*}<0$ when $\gamma<\underline{\gamma}$. The brown monopoly, however, can be sustained at equilibrium only when $p_{H}^{M}>0 \Longleftrightarrow \gamma<\bar{\gamma}^{M}$, as we found in the proof of Lemma 2. Given that $\bar{\gamma}^{M}<\bar{\gamma}$ in $b \in[0, \underline{b}]$, it follows that no producer is active in $\gamma \in\left(\bar{\gamma}^{M}, \bar{\gamma}\right)$. Consider now $\gamma \in[\bar{\gamma}, \underline{\gamma})$. In this region, $p_{L}^{*}<c$ and $p_{H}^{*}<0$. In the proof of Lemma 2, we demonstrated that a brown monopoly does not exist, as $\gamma>\bar{\gamma}^{M}$ and therefore $p_{H}^{M}<0$. Neither the green monopoly can hold at equilibrium, as $p_{L}^{M} \geq c$ only when $\gamma \geq \underline{\gamma}^{M}>\underline{\gamma}$. A similar reasoning can be applied when $\gamma \geq \underline{\gamma}$, where $p_{H}^{*}<0$ and the green monopoly holds at equilibrium for $\gamma \geq \underline{\gamma}^{M}>\underline{\gamma}$. To sum up, no firm is active when $\gamma \in\left(\bar{\gamma}^{M}, \underline{\gamma}^{M}\right)$.

\section{Equilibrium analysis for $q_{H} / q_{L} \geq 2$}

From Section 3, we know that $\widehat{\gamma}>\bar{\gamma} \Longleftrightarrow b<\widehat{b}, \widetilde{\gamma}<\bar{\gamma}$ and $\bar{\gamma}>\underline{\gamma} \Longleftrightarrow b>\underline{b}$. However, when $q_{H} / q_{L} \geq 2$ an additional interval region takes place, given that

$$
\widehat{\gamma}>\widetilde{\gamma}\left\{\begin{array}{l}
\text { always when } q_{H} / q_{L} \in(1,2) \\
\Longleftrightarrow b<\widetilde{b} \equiv \frac{3 c q_{H}}{\left(q_{H}-2 q_{L}\right)\left(q_{H}-q_{L}\right)} \text { when } q_{H} / q_{L} \geq 2
\end{array}\right.
$$

The complete ranking is as follows:

1. $b \in(0, \widehat{b}): \widetilde{\gamma}<\bar{\gamma}<\widehat{\gamma}$, where $\widehat{\gamma}$ does not play any role as the equilibrium changes when $\gamma \geq \bar{\gamma}$, given that the brown producer cannot charge a positive price in the market (see Lemma 2).

2. $b \geq \widehat{b}$ when $q_{H} / q_{L} \in(1,2)$, and $b \in[\widehat{b}, \widetilde{b})$ when $q_{H} / q_{L} \geq 2: \widetilde{\gamma}<\widehat{\gamma}<\bar{\gamma}$, where $\bar{\gamma}$ is not considered as we identified a covered market when $\gamma \geq \widehat{\gamma}$ (see Lemma 1).

3. $q_{H} / q_{L} \geq 2$ and $b \geq \widetilde{b}$, where $\widehat{\gamma}<\widetilde{\gamma}<\bar{\gamma}$, and here both $\widetilde{\gamma}$ and $\bar{\gamma}$ do not play a role as they refer to an internal equilibrium which no longer holds when $\gamma \geq \widehat{\gamma}$.

We focus on the region where $q_{H} / q_{L} \geq 2$ and $b \geq \widetilde{b}$, as the remaining interval region has already been analyzed in the main text. The relevant ranking is here $\widehat{\gamma}<\widetilde{\gamma}<\bar{\gamma}$. Two cases have to be considered:

1. In $\gamma<\widehat{\gamma}$ we have an uncovered duopoly without price switch, given that now $\widehat{\gamma}<\widetilde{\gamma}$. 
2. When $\gamma \geq \widehat{\gamma}$, we have a covered duopoly in $\gamma \in[\widehat{\gamma}, b)$ and a covered green monopoly when $\gamma \geq b$. In this interval region, in fact, $\gamma_{M}<b$, as it can be demonstrated by combining

$$
\gamma_{M}>b \Longleftrightarrow b<\frac{c}{q_{H}-2 q_{L}} \equiv b^{M}
$$

with the fact that $b^{M}<\widetilde{b}$. Hence, an uncovered green monopoly cannot be obtained at equilibrium. As for the covered duopoly, the price switch occurs in $\gamma \in[b / 3, b)$, as:

$$
p_{H}^{C}>p_{L}^{C} \Longleftrightarrow \gamma<b / 3 \text {, and } b / 3>\widehat{\gamma} \Longleftrightarrow b \geq \widetilde{b} \text {. }
$$

Hence, in $\gamma \in[\widehat{\gamma}, b / 3)$, we obtain a covered duopoly at the limit without price switch.

\section{Profits at the duopoly equilibrium: the role of $b$ and $\gamma$}

When the duopoly is sustained by an interior equilibrium, prices are given by (6) and (7). It is immediate to find that:

$$
\frac{\partial p_{L}^{*}}{\partial b}>0, \frac{\partial p_{H}^{*}}{\partial b}>0, \frac{\partial p_{L}^{*}}{\partial \gamma}>0, \frac{\partial p_{H}^{*}}{\partial \gamma}<0
$$

Notice that $\partial p_{H}^{*} / \partial b>\partial p_{L}^{*} / \partial b$, given that $q_{H}>q_{L}$. At the same time, $p_{L}^{*}$ increases in $\gamma$ whereas $p_{H}^{*}$ decreases in $\gamma$. Demand functions at equilibrium, whose precise value is reported in Table 1 , are denoted as $x_{L}^{*}$ and $x_{H}^{*}$. We find that:

$$
\begin{aligned}
\frac{\partial x_{H}^{*}}{\partial b}>0 \Leftrightarrow \gamma>\gamma_{1}=\frac{c q_{H}}{3 q_{H}^{2}-4 q_{H} q_{L}+q_{L}^{2}}, \\
\frac{\partial x_{L}^{*}}{\partial b}>0 \Leftrightarrow \gamma<\gamma_{2}=\frac{c\left(2 q_{H}-q_{L}\right)}{2 q_{H}\left(q_{H}-q_{L}\right)}, \\
\frac{\partial x_{L}^{*}}{\partial \gamma}>0, \frac{\partial x_{H}^{*}}{\partial \gamma}<0 .
\end{aligned}
$$

Moreover, taking into account that an uncovered duopoly holds when $\gamma \in[\max \{0, \underline{\gamma}\}, \min \{\bar{\gamma}, \widehat{\gamma}\}$ ) (see Lemma 1), we obtain that:

$$
\begin{aligned}
& \gamma_{1} \in[\max \{0, \underline{\gamma}\}, \min \{\bar{\gamma}, \widehat{\gamma}\}) \Leftrightarrow b \geq \frac{c\left(4 q_{H}-q_{L}\right)}{q_{L}\left(3 q_{H}-q_{L}\right)}>\underline{b}, \\
& \gamma_{2} \in[\max \{0, \underline{\gamma}\}, \min \{\bar{\gamma}, \widehat{\gamma}\}) \Leftrightarrow b \geq \frac{c\left(4 q_{H}-q_{L}\right)}{4 q_{H}^{2}}>\underline{b} .
\end{aligned}
$$

Finally, turning to equilibrium profits $\pi_{L}^{*}$ and $\pi_{H}^{*}$ (see Table 1 for precise expressions):

$$
\begin{aligned}
\frac{\partial \pi_{L}^{*}}{\partial b}>0 \Leftrightarrow \gamma<\check{\gamma}=\frac{c\left(2 q_{H}-q_{L}\right)+b q_{L}\left(q_{H}-q_{L}\right)}{2 q_{H}\left(q_{H}-q_{L}\right)}, \frac{\partial \pi_{H}^{*}}{\partial b}>0 \\
\frac{\partial \pi_{L}^{*}}{\partial \gamma}>0, \frac{\partial \pi_{H}^{*}}{\partial \gamma}<0 .
\end{aligned}
$$

Observe that:

$$
\begin{aligned}
& \check{\gamma} \in[\max \{0, \underline{\gamma}\}, \min \{\bar{\gamma}, \widehat{\gamma}\}) \Leftrightarrow b \geq \frac{c\left(4 q_{H}-q_{L}\right)}{4 q_{H}^{2}-3 q_{H} q_{L}+q_{L}^{2}}, \\
& \check{\gamma}>\gamma_{2}>\gamma_{1} .
\end{aligned}
$$

We can summarize the above results by distinguishing between four parametric regions: 
- $\gamma<\gamma_{1}$ : the model behaves as in a traditional setting of (hedonic) vertical differentiation. When $b$ increases, both $p_{H}^{*}$ and $p_{L}^{*}$ go up, with the former increasing more than the latter. As a consequence, $x_{H}^{*}$ decreases, whereas $x_{L}^{*}$ increases. Notwithstanding the fact that $\partial x_{H}^{*} / \partial b<0$, the profit of the brown firm increases in $b\left(\partial \pi_{H}^{*} / \partial b>0\right)$, meaning that the price surge overcomes the demand contraction. As for the green firm, $\partial x_{L}^{*} / \partial b>0$ as it gains more consumers "at the right-end" than those which loses "at the left-end" of the market (as $p_{L}^{*}$ increases).

- $\gamma \in\left[\gamma_{1}, \gamma_{2}\right)$ : the value of $\gamma$ is intermediate and neither vertical (hedonic/environmental) dimension prevails so that horizontal differentiation takes place. For this reason, not only $\partial x_{L}^{*} / \partial b>0$ but also $\partial x_{H}^{*} / \partial b>0$. As a consequence, both $\partial \pi_{H}^{*} / \partial b>0$ and $\partial \pi_{L}^{*} / \partial b>0$.

- $\gamma \in\left[\gamma_{2}, \check{\gamma}\right): \gamma$ is sufficiently high to outweigh the hedonic attribute, therefore inverting the quality ranking as vertical environmental differentiation prevails. This explains why $\partial x_{L}^{*} / \partial b<0$ and $\partial x_{H}^{*} / \partial b>0$. However, the overall effect is such that $\partial \pi_{L}^{*} / \partial b>0$; when $b$ increases, for the green firm the price surge $\left(\partial p_{L}^{*} / \partial b>0\right)$ dominates the demand contraction $\left(\partial x_{L}^{*} / \partial b<0\right)$.

- $\gamma \geq \check{\gamma}$ : $\gamma$ is very high. The forces at work are the same as in the previous interval, with the relevant exception that now for the green firm the demand reduction prevails over the price increase, thus explaining why $\partial \pi_{L}^{*} / \partial b<0$.

Consider now the corner duopoly with market coverage. Equilibrium prices are given by (12) and (13). Notice that $p_{L}^{C}$ does not change in $b$ (as, in this constrained equilibrium, it coincides with the valuation of consumer type zero), while it obviously increases in $\gamma$. As for $p_{H}^{C}$, it increases in $b$ but decreases in $\gamma$, as expected. Demand functions $x_{L}^{C}$ and $x_{H}^{C}$ are reported in Table 1, as well as equilibrium profits $\pi_{L}^{C}$ and $\pi_{H}^{C}$. First, it is immediate to compute the following derivatives:

$$
\frac{\partial x_{L}^{C}}{\partial b}<0, \frac{\partial x_{H}^{C}}{\partial b}>0 \text { and } \frac{\partial x_{L}^{C}}{\partial \gamma}>0, \frac{\partial x_{H}^{C}}{\partial \gamma}<0
$$

As one can see, $\partial x_{L}^{C} / \partial b=-\partial x_{H}^{C} / \partial b$ and $\partial x_{L}^{C} / \partial \gamma=-\partial x_{H}^{C} / \partial \gamma$. Then, according to the previous discussion, we find that:

$$
\frac{\partial \pi_{L}^{C}}{\partial b}<0, \frac{\partial \pi_{H}^{C}}{\partial b}>0 \text { and } \frac{\partial \pi_{L}^{C}}{\partial \gamma}>0, \frac{\partial \pi_{H}^{C}}{\partial \gamma}<0
$$

\section{Proof of Proposition 3}

(i) The proof directly follows from observing the total damage defined in (16) for the case of covered duopoly and that in (17) for the case of green uncovered monopoly. 
(ii) In the unconstrained duopoly equilibrium, calculations are more complex. In particular, the environmental damage computed at the equilibrium is:

$$
\begin{aligned}
D_{D} & =D_{D}^{L}+D_{D}^{H}=q_{L} x_{L}^{*}+q_{H} x_{H}^{*}, \text { where } \\
D_{D}^{L} & =\frac{q_{H}\left(c q_{L}-2 c q_{H}+b q_{H} q_{L}-2 \gamma q_{H} q_{L}-b q_{L}^{2}+2 \gamma q_{H}^{2}\right)}{b\left(q_{L}-q_{H}\right)\left(q_{L}-4 q_{H}\right)} \\
D_{D}^{H} & =\frac{q_{H}\left(2 b q_{H} q_{L}-c q_{H}-4 \gamma q_{H} q_{L}-2 b q_{H}^{2}+3 \gamma q_{H}^{2}+\gamma q_{L}^{2}\right)}{b\left(q_{H}-q_{L}\right)\left(q_{L}-4 q_{H}\right)} .
\end{aligned}
$$

We proceed by studying the sign of the partial derivatives of $D_{D}^{L}$ and $D_{D}^{H}$ w.r.t. $q_{H}$. First of all, notice that

$$
\frac{\partial D_{D}^{L}}{\partial q_{H}}=\frac{\partial q_{L}}{\partial q_{H}} x_{L}+\frac{\partial x_{L}}{\partial q_{H}} q_{L} \propto \frac{\partial x_{L}}{\partial q_{H}}
$$

given that $\left(\partial q_{L} / \partial q_{H}\right) x_{L}=0$. In particular:

$$
\frac{\partial x_{L}}{\partial q_{H}}>0 \Longleftrightarrow \gamma>\frac{q_{L}\left[b q_{L}\left(q_{H}-q_{L}\right)^{2}-c\left(6 q_{H}^{2}-4 q_{H} q_{L}+q_{L}^{2}\right)\right]}{4 q_{H}\left(2 q_{H}-q_{L}\right)\left(q_{L}-q_{H}\right)^{2}} \equiv \gamma_{3},
$$

where $\gamma_{3}<\min \{\bar{\gamma}, \widehat{\gamma}\}$. Then, we evaluate:

$$
\frac{\partial D_{D}^{H}}{\partial q_{H}}=\frac{\partial q_{H}}{\partial q_{H}} x_{H}+\frac{\partial x_{H}}{\partial q_{H}} q_{H}=x_{H}+\frac{\partial x_{H}}{\partial q_{H}} q_{H},
$$

where $\partial x_{H} / \partial q_{H}<0$ in the parametric region under consideration. It follows that the sign of $\partial D_{D}^{H} / \partial q_{H}$ is ambiguous. Direct computations reveal that:

$$
\frac{\partial D_{D}^{H}}{\partial q_{H}}>0 \Longleftrightarrow \gamma<\frac{q_{H}\left[4 b\left(2 q_{H}-q_{L}\right)\left(q_{H}-q_{L}\right)^{2}-c\left(5 q_{H}-2 q_{L}\right) q_{L}\right]}{\left(12 q_{H}^{2}+q_{L}^{2}-6 q_{H} q_{L}\right)\left(q_{H}-q_{L}\right)^{2}} \equiv \gamma_{4},
$$

where $\gamma_{4} \in\left(\gamma_{3}, \bar{\gamma}\right)$. Finally, considering total damage:

$$
\frac{\partial D_{D}}{\partial q_{H}}=\frac{\partial D_{D}^{L}}{\partial q_{H}}+\frac{\partial D_{D}^{H}}{\partial q_{H}}=\frac{\partial x_{L}}{\partial q_{H}} q_{L}+x_{H}+\frac{\partial x_{H}}{\partial q_{H}} q_{H}
$$

The sign is again ambiguous. We find that:

$$
\frac{\partial D_{D}}{\partial q_{H}}>0 \Longleftrightarrow \gamma<\frac{4 b q_{H}\left(2 q_{H}-q_{L}\right)+q_{L}\left(c-b q_{L}\right)}{4 q_{H}^{2}+q_{L}^{2}-2 q_{H} q_{L}} \equiv \gamma_{P},
$$

where additional subscript $P$ indicates pollution, as such threshold value of $\gamma$ is particularly relevant in terms of the environmental damage. One can easily verify that $\gamma_{P}>\gamma_{4}>\gamma_{3}$. Interestingly, notice that $\gamma_{P}>\hat{\gamma}$, and that $\gamma_{P}<\bar{\gamma}$ only when $b<b_{P} \equiv c\left(q_{H}^{2}-q_{H} q_{L}+q_{L}^{2}\right) /\left(4 q_{H}+q_{L}\right)\left(q_{H}-q_{L}\right)^{2}$. Moreover, $b_{P}>\underline{b}$ only when $q_{H} / q_{L}<2$. Hence, $\gamma_{P}>\bar{\gamma}$ when $q_{H} / q_{L} \geq 2$, meaning that $\gamma_{P}$ lies outside the relevant parametric region. Summing up:

(a) when $q_{H} / q_{L}<2, \partial D_{D} / \partial q_{H}>0$ for each value of $\gamma$ when $b \geq b_{P}$, as we have that $\gamma_{3}<\gamma_{4}<$ $\bar{\gamma}<\gamma_{P}$. In $b \in\left(\underline{b}, b_{P}\right)$, threshold value $\gamma_{P}$ becomes relevant, as $\gamma_{3}<\gamma_{4}<\gamma_{P}<\bar{\gamma}$; it follows that 
$\partial D_{D} / \partial q_{H}>0$ when $\gamma<\gamma_{P}$, and $\partial D_{D} / \partial q_{H}<0$ when $\gamma \in\left[\gamma_{P}, \bar{\gamma}\right]$. More precisely, for $\gamma \in\left[\gamma_{P}, \bar{\gamma}\right]$ : $\partial D_{D}^{L} / \partial q_{H}>0, \partial D_{D}^{H} / \partial q_{H}<0, \partial D_{D} / \partial q_{H}<0$.

(b) When $q_{H} / q_{L} \geq 2, \partial D_{D} / \partial q_{H}>0$ for every value of $b$.

\section{Absolute preferences}

When the market is characterized by an uncovered duopoly, equilibrium prices are:

$$
\begin{aligned}
p_{L}^{* \prime} & =\frac{2 c q_{H}+\left(q_{H}-q_{L}\right)\left[2 \gamma q_{H}+(b-\mu) q_{L}\right]}{4 q_{H}-q_{L}}, \\
p_{H}^{* \prime} & =\frac{c q_{H}+\left(q_{H}-q_{L}\right)\left[2 b q_{H}-\gamma\left(3 q_{H}-q_{L}\right)-2 q_{H} \mu\right]}{4 q_{H}-q_{L}} .
\end{aligned}
$$

Plugging these prices into the respective demand functions, we obtain equilibrium market shares:

$$
\begin{aligned}
x_{L}^{* \prime} & =\frac{q_{H}\left[\left(q_{H}-q_{L}\right)\left(2 \gamma q_{H}+b q_{L}-\mu q_{L}\right)-c\left(2 q_{H}-q_{L}\right)\right]}{b q_{L}\left(4 q_{H}-q_{L}\right)\left(q_{H}-q_{L}\right)}, \\
x_{H}^{* \prime} & =\frac{c q_{H}+\left(q_{H}-q_{L}\right)\left[2 q_{H}(b-\mu)-\gamma\left(3 q_{H}-q_{L}\right)\right]}{b\left(4 q_{H}-q_{L}\right)\left(q_{H}-q_{L}\right)} .
\end{aligned}
$$

Similarly, when the duopoly market is covered, equilibrium prices and market shares can be easily calculated:

$$
\begin{gathered}
p_{L}^{C \prime}=\gamma\left(q_{H}-q_{L}\right)-\mu q_{L}, p_{H}^{C \prime}=\frac{1}{2}\left[(b-\gamma)\left(q_{H}-q_{L}\right)-q_{H} \mu\right] ; \\
x_{L}^{C \prime}=\frac{\left(q_{H}-q_{L}\right)(b+\gamma)+\mu q_{H}}{2 b\left(q_{H}-q_{L}\right)}, x_{H}^{C \prime}=\frac{\left(q_{H}-q_{L}\right)(b-\gamma)-\mu q_{H}}{2 b\left(q_{H}-q_{L}\right)} .
\end{gathered}
$$

Comparing market shares in both the uncovered and the covered case with the corresponding ones in the baseline model (see Table 1), we obtain:

$$
x_{L}^{* \prime}-x_{L}^{*}=-\frac{q_{H} \mu}{\left(4 q_{H}-q_{L}\right) b}<0, x_{H}^{* \prime}-x_{H}^{*}=-\frac{2 q_{H} \mu}{\left(4 q_{H}-q_{L}\right) b}<0 ;
$$

and

$$
x_{L}^{C \prime}-x_{L}^{C}=\frac{q_{H} \mu}{2\left(q_{H}-q_{L}\right) b}>0, x_{H}^{C \prime}-x_{H}^{C}=-\frac{q_{H} \mu}{2 b\left(q_{H}-q_{L}\right)}<0 .
$$

This confirms that, with respect to the baseline model, both market shares are reduced when the market is uncovered, while the green firm expands its market at the expense of the rival when the market is covered.

\section{Horizontal differentiation}

The assumption that must hold throughout the analysis is the following:

\section{Assumption 1}

$$
\alpha<\min \left\{\frac{1}{q_{L}}\left(p_{H} q_{L}-p_{L} q_{H}\right), \frac{2 p_{L} q_{L}}{q_{L}+\lambda\left(q_{H}+q_{L}\right)}\right\} .
$$


As we know from the extension of Subsection 5.2, for the fraction $\lambda$ of the population the demand for the brown good $H$ expands at the expense of the green rival $L$, due to the presence of the horizontal component $\alpha$. However, the value of $\alpha$ cannot be to high. Indeed:

$$
\theta_{H}^{H}>\theta_{L}^{H} \Leftrightarrow \alpha<\frac{1}{q_{L}}\left(p_{H} q_{L}-p_{L} q_{H}\right)
$$

Therefore, Assumption 1 guarantees that vertical differentiation is preserved for the fraction $\alpha$ of consumers who prefer brand $H$. It is also immediate to verify that, under such assumption, it always holds that $\theta_{H}^{L}>\theta_{L}^{L}$. In other words, the horizontal component $\alpha$ does not invert the hedonic vertical attribute of the model when we consider the $(1-\lambda)$ fraction of consumers who prefer brand $L$. Finally, when computing total demand functions, we find that:

$$
\begin{aligned}
x_{H}^{\prime}= & \frac{(b-2 \gamma)\left(q_{H}-q_{L}\right)-\left(p_{H}-p_{L}\right)-\alpha(1-2 \lambda)}{b\left(q_{H}-q_{L}\right)}, \\
x_{L}^{\prime}= & \left\{\begin{array}{c}
\frac{\gamma\left(q_{H}-q_{L}\right)\left(q_{H}+q_{L}\right)+\alpha\left[q_{H}-\lambda\left(q_{H}+q_{L}\right)\right]-p_{L} q_{H}+p_{H} q_{L}}{b\left(q_{H}-q_{L}\right) q_{L}} \text { if } \gamma<\frac{p_{L}-\alpha}{q_{H}-q_{L}}, \\
\frac{\gamma(2+\lambda)\left(q_{H}-q_{L}\right)^{2}+q_{L}\left(p_{H}-p_{L}+\alpha\right)-\lambda\left[p_{L}\left(q_{H}-q_{L}\right)-2 q_{L}\right]}{b\left(q_{H}-q_{L}\right) q_{L}} \text { if } \gamma \in\left[\frac{p_{L}-\alpha}{q_{H}-q_{L}}, \frac{p_{L}}{q_{H}-q_{L}}\right), \\
\frac{p_{H}-p_{L}+2 \gamma\left(q_{H}-q_{L}\right)+\alpha(1-2 \lambda)}{b\left(q_{H}-q_{L}\right)} \text { if } \gamma \geq \frac{p_{L}}{q_{H}-q_{L}} .
\end{array}\right.
\end{aligned}
$$

Also in this setting the defining property of vertical differentiation can cease to hold. In particular,

$$
\begin{gathered}
\left.x_{H}^{\prime}\right|_{p_{H}=p_{L}}=\frac{(b-2 \gamma)\left(q_{H}-q_{L}\right)-\alpha(1-2 \lambda)}{b\left(q_{H}-q_{L}\right)} \geq 0 \Leftrightarrow \gamma \leq \frac{b}{2}-\frac{\alpha(1-2 \lambda)}{2\left(q_{H}-q_{L}\right)} \equiv \gamma_{H}^{H}, \\
\left.x_{L}^{\prime}\right|_{p_{H}=p_{L}}=\left\{\begin{array}{c}
\frac{\gamma\left(q_{H}-q_{L}\right)\left(q_{H}+q_{L}\right)+\alpha\left[q_{H}-\lambda\left(q_{H}+q_{L}\right)\right]-p_{L}\left(q_{H}-q_{L}\right)}{b\left(q_{H}-q_{L}\right) q_{L}} \text { if } \gamma<\frac{p_{L}-\alpha}{q_{H}-q_{L}}, \\
\frac{\gamma}{b}(2+\lambda)\left(\frac{q_{H}-q_{L}}{q_{L}}\right)_{L}+\frac{q_{L}(\alpha-2 \lambda)-\lambda p_{L}\left(q_{H}-q_{L}\right)}{b\left(q_{H}-q_{L}\right) q_{L}} \text { if } \gamma \in\left[\frac{p_{L}-\alpha}{q_{H}-q_{L}}, \frac{p_{L}}{q_{H}-q_{L}}\right), \\
\frac{2 \gamma\left(q_{H}-q_{L}\right)+\alpha(1-2 \lambda)}{b\left(q_{H}-q_{L}\right)} \text { if } \gamma \geq \frac{p_{L}}{q_{H}-q_{L}} .
\end{array}\right.
\end{gathered}
$$

Under Assumption 1, it is possible to verify that $\alpha<\frac{2 p_{L} q_{L}}{q_{L}+\lambda\left(q_{H}+q_{L}\right)}$ guarantees that: ${ }^{57}$

$$
\left.x_{L}^{\prime}\right|_{p_{H}=p_{L}} \geq 0 \Leftrightarrow \gamma \geq \frac{p_{L}\left(q_{H}-q_{L}\right)+\alpha\left[\lambda q_{L}-(1-\lambda) q_{H}\right]}{\left(q_{H}-q_{L}\right)\left(q_{H}+q_{L}\right)} \equiv \gamma_{L}^{L}<\frac{p_{L}-\alpha}{q_{H}-q_{L}} .
$$

Notice that $\gamma_{H}^{H}>\gamma_{L}^{L} \Leftrightarrow b>\frac{2 p_{L}-\alpha}{q_{H}+q_{L}} \equiv b_{D}^{\prime}\left(p_{L}\right)$. Hence, when $b>b_{D}^{\prime}\left(p_{L}\right)$, at equal prices, at least one firm is active in the market for any value of $\gamma$. Indeed, for $\gamma<\gamma_{L}^{L}$, (resp. $\left.\gamma>\gamma_{H}^{H}\right),\left.x_{H}^{\prime}\right|_{p_{H}=p_{L}}>0$ and $\left.x_{L}^{\prime}\right|_{p_{H}=p_{L}}=0$ (resp. $\left.x_{H}^{\prime}\right|_{p_{H}=p_{L}}=0$ and $\left.x_{L}^{\prime}\right|_{p_{H}=p_{L}}>0$ ); for $\gamma \in\left[\gamma_{L}^{L}, \gamma_{H}^{H}\right],\left.x_{H}^{\prime}\right|_{p_{H}=p_{L}}>0$ and $\left.x_{L}^{\prime}\right|_{p_{H}=p_{L}}>0$ so that the defining property of horizontal differentiation occurs. In order to compare the present setting with the baseline model, focusing on the case $b>b_{D}$, it can be proven that:

$$
\begin{aligned}
\gamma_{H}^{H}>\gamma_{H} & \Longleftrightarrow \lambda>\frac{1}{2}, \\
\gamma_{L}^{L}>\gamma_{L} & \Longleftrightarrow \lambda>\lambda_{1} .
\end{aligned}
$$

${ }^{57}$ Additional calculations are available upon request, together with the complete derivation of total demand functions. 
Then, with respect to the baseline model, we can state the following.

(i) When $\lambda \in(0,1 / 2): \gamma_{H}^{H} \leq \gamma_{H}$ and $\gamma_{L}^{L} \leq \gamma_{L}$. The parametric interval where vertical hedonic differentiation occurs reduces, while that of vertical environmental differentiation enlarges, given that:

$$
\left(\gamma_{H}-\gamma_{H}^{H}\right)-\left(\gamma_{L}-\gamma_{L}^{L}\right)=\left(-\frac{1}{2}\right)\left(q_{H}+q_{L}\right)^{-1} \alpha<0 .
$$

(ii) When $\lambda \in\left[1 / 2, \lambda_{1}\right): \gamma_{L}^{L} \leq \gamma_{L}$ and $\gamma_{H}^{H}>\gamma_{H}$. Both intervals of vertical differentiation reduce. Therefore, the interval of horizontal differentiation enlarges.

(iii) When $\lambda \in\left(\lambda_{1}, 1\right): \gamma_{L}^{L}>\gamma_{L}$ and $\gamma_{H}^{H}>\gamma_{H}$. With respect to the baseline model, vertical hedonic differentiation is observed in a wider parametric interval, while the opposite holds for vertical environmental differentiation. The interval of horizontal differentiation moves rightward and increases.

\section{References}

[1] Andreoni, J. (1988). Privately provided public goods in a large economy: the limits of altruism. Journal of Public Economics, 35 (1), pp. 57-73.

[2] Andreoni, J. (1990). Impure altruism and donations to public goods: a theory of warm-glow giving. The Economic Journal, 100 (401), pp. 464-477.

[3] Bagwell, L. S. and B. D. Bernheim (1996). Veblen Effects in a Theory of Conspicuous Consumption. The American Economic Review, 86 (3), pp. 349-373.

[4] Bateson M., Nettle D. and G. Roberts (2006). Cues of being watched enhance cooperation in a real-world setting. Biology Letters, 2 (3), pp. 412-414.

[5] Ben Elhadj, N., Gabszewicz J.J. and O. Tarola (2015). Social awareness and price competition. International Journal of Economic Theory, 11 (1), pp. 75-88.

[6] Ben Elhadj, N. and O. Tarola (2015). Relative quality-related (dis)utility in vertically differentiated oligopoly with an environmental externality. Environment and Development Economics, 20 (3), pp. 354-379.

[7] Boucekkine R., Krawczyk J. B., and T. Vall (2011) Environmental quality versus economic performance: A dynamic game approach. Optimal Control Applications and Methods, 32 (1), pp. 29-46.

[8] Bowles, S. and Y. Park (2005). Emulation, Inequality, and Work Hours: Was Thorsten Veblen Right?. The Economic Journal, 115 (507), pp. 397-412.

[9] Brekke, K.A., Kverndokk, S. and K. Nyborg (2003). An Economic Model of Moral Motivation. Journal of Public Economics, 87 (9-10), pp. 1967-1983. 
[10] Carlsson, F., Garcia, J. and Å. Löfgren (2010). Conformity and the Demand for Environmental Goods. Environmental and Resource Economics, 47 (3), pp. 407-421, November.

[11] Carrigan, M. and A. Attalla (2001). The Myth of the Ethical Consumer - Do Ethics Matter in Purchase Behavior. Journal of Consumer Marketing, 18 (7), pp. 560-577.

[12] Clemenz, G. (2010). Eco-Labeling and Horizontal Product Differentiation. Environmental and Resource Economics, 45 (4) , pp. 481-497.

[13] Conrad K. (2005). Price Competition and Product Differentiation When Consumers Care for the Environment. Environmental and Resource Economics, 31 (1), pp. 1-19.

[14] Crampes, C., and A. Hollander (1995), Duopoly and quality standards. European Economic Review, 39 (1), pp. 71-82.

[15] Deltas, G., Harrington, D. R. and M. Khanna (2013). Oligopolies with (Somewhat) Environmentally Conscious Consumers: Market Equilibrium and Regulatory Intervention. Journal of Economics and Management Strategy, 22 (3), pp. 640-667.

[16] Ecchia G., and L. Lambertini (1997). Minimum Quality Standards and Collusion. Journal of Industrial Economics, 44 (1), pp. 101-113.

[17] Eriksson, C. (2004). Can Green Consumerism Replace Environmental Regulation? a Differentiated Products Example. Resource and Energy Economics, 26 (3), pp. 281-293.

[18] Espìnola-Arredendo, A. and H. Zhao (2012). Environmental policy in a linear city model of product differentiation. Environment and Development Economics, 17 (4), pp. 461-477.

[19] Frondel, M., Horbach J. and Renning K. (2007) End-of-pipe or cleaner production? An empirical comparison of environmental innovation decisions across OECD countries. Business Strategy and the Environment, 16 (8), pp. 571-584.

[20] Gabszewicz, J.J., Marini M. and O. Tarola (2016). Vertical Differentiation and Collusion: Cannibalization or Proliferation?. FEEM, WP 15.

[21] Gabszewicz, J.J. and J.F. Thisse (1986), On the nature of competition with differentiated products. The Economic Journal, 96 (381), pp. 160-172.

[22] Gabszewicz, J.J. and X. Wauthy (2012), Nesting horizontal and vertical differentiation. Regional Science and Urban Economics, 42 (6), pp. 998-1002.

[23] García-Gallego, A. and N. Georgantzís (2009). Market Effects of Changes in Consumers' Social Responsibility. Journal of Economics and Management Strategy, 18 (1), pp. 235-262.

[24] Gupta, S. and G. T. Ogden (2009). To buy or not to buy? A social dilemma perspective on green buying. Journal of Consumer Marketing, 26 (6), pp. 376-391. 
[25] Heffner R., Kurani, K. S. and T. S. Turrentine (2007). Symbolism in California's Early market for Hybrid Electric Vehicles. Transportation Research Part D, 12 (6), pp. 396-413.

[26] Lambertini, L. (2013). Oligopoly, the Environment and Natural Resources, London, Routledge.

[27] Lauga, D. and E. Ofek (2011). Product Positioning in a Two-Dimensional Vertical Differentiation Model: The Role of Quality Costs. Marketing Science, 30 (5), pp. 903-923.

[28] Lombardini-Riipinen C. (2005). Optimal Tax Policy under Environmental Quality Competition. Environmental and Resource Economics, 32 (3), pp. 317-336.

[29] Luken, R., Kumar, R., and Artacho-Garces, J. (1996). The Effect of Environmental Regulations on Industrial Competitiveness of Selected Industries in Developping Countries", Paper Presented at the 5th Greening of Industry International Conference: Global Restructuring: a Place for Ecology?, Heidelberg, Germany, November.

[30] Manner, M. and J. Gowdy (2010). The evolution of social and moral behavior: evolutionary insights for public policy. Ecological Economics, 69 (4), pp. 753-761.

[31] Mantovani, A. and C. Vergari (2013), Hedonic vs Environmental Quality: Which Policy Can Help in Lowering Pollution Emissions? Working paper 905, Department of Economics, University of Bologna.

[32] Milinski, M., D. Semmann, H-J. Kramback, and J. Marotzke. (2006). Stabilizing the Earth's climate is not a losing game: Supporting evidence from public good experiments. Proceedings of the National Academy of Sciences, 103 (11), pp. 3994-3998.

[33] Moraga-Gonzalez, J. L. and N. Padron-Fumero (2002). Environmental Policy in a Green Market. Environmental and Resource Economics, 22 (3), pp. 419-447.

[34] Mussa, M. and S. Rosen (1978). Monopoly and product quality. Journal of Economic Theory, 18, 301-317.

[35] Neven, D., Thisse, J. (1990). On quality and variety competition. In: Gabszewicz, J., Richard, J.F., Wolsey, L. (Eds.), Economic Decision Making: Games, Econometrics and Optimization; Contributions in Honour of Jacques Dréze, pp. 175-199.

[36] Nyborg, K., Howarth R.B. and K.A. Brekke (2006). Green Consumers and Public Policy: On Socially Contingent Moral Motivation. Resource and Energy Economics, 28 (4), pp. 351-366.

[37] Ostrom, E. (2000). Collective Action and the Evolution of Social Norms. The Journal of Economic Perspectives, 14 (3), pp. 137-158.

[38] Owen, A.L. and J. Videras (2006). Civic cooperation, proenvironment attitudes, and behavioral intentions. Ecological Economics, 58 (4), pp. 814-829.

[39] Porter, M.E. and C. van der Linde (1995). Toward a New Conception of the EnvironmentCompetitiveness Relationship. The Journal of Economic Perspectives 9, (4), pp. 97-118. 
[40] Rodriguez-Ibeas, R. (2007). Environmental Product Differentiation and Environmental Awareness. Environmental and Resource Economics, 36 (2), pp. 237-254.

[41] Ronnen, U. (1991). Minimum quality standards, fixed costs, and competition. Rand Journal of Economics, 22 (4), pp. 490-504.

[42] Scarpa, C. (1998). Minimum quality standards with more than two firms. International Journal of Industrial Organization 16 (5), pp. 665-676.

[43] Turaga R. M. R., Howarth, R. B. and M.E. Borsuk (2010). Pro-environmental behavior: rational choice meets moral motivation. Annals of the New York Academy of Science, 1185, pp. 211224.

[44] Vandenbosch, M.B., and C. B. Weinberg. Product and Price Competition in a Two-Dimensional Vertical Differentiation Model. Marketing Science, 14 (2), pp. 224-249.

[45] Veblen, T. (1899). Theory of the Leisure Class: An Economic Study in the Evolution of Institutions. New York: Macmillan.

[46] Wauthy, X. (1996). Quality Choice in Models of Vertical Differentiation. Journal of Industrial Economics, 44 (3), pp. 345-53.

[47] Weatherell, C., Tregear, A. and J. Allinson (2003), In Search of the Concerned Consumer: UK Public Perceptions of Food, Farming and Buying Local. Journal of Rural Studies, 19 (2), pp. 233-244. 